\title{
OCORRÊNCIA DE PATÓGENOS EM CARNÍVOROS SELVAGENS BRASILEIROS E SUAS IMPLICAÇÕES PARA A CONSERVAÇÃO E SAÚDE PÚBLICA
}

\author{
Rodrigo Silva Pinto Jorge ${ }^{1,2}$, Fabiana Lopes Rocha ${ }^{2,3}$, Joares Adenilson May Júnior ${ }^{4}$ \& Ronaldo \\ Gonçalves Morato \\ ${ }^{1}$ Reserva Extrativista Mãe Grande de Curuçá - Instituto Chico Mendes de Conservação da Biodiversidade. Av. Julio Cesar, 7060 - Val de Cans, Belém- \\ PA, Brasil. CEP 66617-420. \\ ${ }^{2}$ Instituto Brasileiro de Medicina da Conservação - Rua Silveira Lobo, 32, Caixa Postal 48, Bairro Casa Forte, Recife-PE, CEP: $52061-030$. \\ ${ }^{3}$ Programa de Pós-graduação em Biologia Parasitária. Laboratório de Biologia de Tripanosomatídeos e Laboratório de Biologia e Parasitologia de \\ Mamíferos Silvestres Reservatórios. Fundação Oswaldo Cruz. Av. Brasil, 4365 Manguinhos Pavilhão Rocha Lima $5^{\circ}$ andar. Rio de Janeiro-RJ, Brasil. \\ CEP: 21040-900. \\ ${ }^{4}$ Programa de Pós-graduação do Departamento de Medicina Veterinária Preventiva e Saúde Animal (VPS), Faculdade de Medicina Veterinária e \\ Zootecnia da Universidade de São Paulo (USP) - Av. Prof. Dr. Orlando Marques de Paiva, 87, Cidade Universitária, São Paulo-SP, Brasil. \\ CEP: 05508-270. \\ ${ }^{5}$ Centro Nacional de Manejo e Conservação de Mamíferos Carnívoros - Instituto Chico Mendes de Conservação da Biodiversidade (CENAP/ICMBio). \\ Estrada Hisaichi Takebayashi, 8600, Atibaia-SP, CEP: 12952-011. \\ E-mails: rspjorge@gmail.com,rochabia2@yahoo.com.br, joaresmay@ig.com.br, ronaldo.morato@icmbio.gov.br
}

\section{RESUMO}

Diversos surtos epidêmicos causados por agentes patogênicos provocaram severo declínio em populações de carnívoros selvagens nas últimas décadas. Além deste impacto às populações silvestres, há a preocupação da transmissão de alguns destes agentes à população humana e de animais domésticos. De fato, as alterações ambientais têm provocado mudanças na relação patógeno-hospedeiro. Desta forma, o monitoramento da saúde de animais silvestres é importante componente no estabelecimento de programas de controle e erradicação de doenças e na elaboração de políticas de saúde pública e animal e de manejo e conservação de espécies selvagens. Considerando o papel dos mamíferos da ordem Carnivora na cadeia trófica, estes podem ser usados como "sentinelas", sendo alvos estratégicos em programas de vigilância para detecção de patógenos. Neste artigo serão revisados estudos de caso dos principais patógenos que acometem carnívoros selvagens, com ênfase nas espécies da fauna brasileira. Os métodos laboratoriais utilizados nos estudos de exposição dos carnívoros brasileiros a patógenos serão discutidos e considerações sobre estratégias para minimizar seus impactos sobre a fauna silvestre, bem como os possíveis métodos para controle de patógenos causadores de zoonoses em carnívoros.

Palavras-chave: Ordem Carnivora; medicina da conservação; zoonoses; epidemiologia; manejo de fauna.

\begin{abstract}
OCCURRENCE OF PATHOGENS IN BRAZILIAN WILD CARNIVORES AND ITS IMPLICATIONS FOR CONSERVATION AND PUBLIC HEALTH. Several outbreaks caused by pathogens caused declines in wild carnivore populations in the last decades. In addition to the negative impact to wild populations, there is a concern about the transmission of some of these agents to humans and domestic animals. In fact, environmental alterations have resulted in changes in the pathogen-host relation. Therefore, monitoring health of wild animals is considered an important component in programs for control or eradication of diseases and in the public and animal health politics and for the management and conservation of wild species. Considering the role of mammals of the order Carnivora in the trophic chain, they might be used as "sentinels", working as strategic targets in programs of surveillance of important pathogens for public and animal health. We review in this paper case-studies of the main pathogens that occur in wild carnivores,
\end{abstract}


emphasizing species of the Brazilian fauna. We also discuss laboratorial methods used in studies of exposure of Brazilian wild carnivores to pathogens, as well as strategies to minimize the impacts in these populations caused by that exposure, and methods for controlling the occurrence of zoonotic pathogens in wild carnivores.

Keywords: Order Carnivora; conservation medicine; zoonosis; epidemiology; fauna management.

\section{RESUMEN}

OCURRENCIA DE PATÓGENOS EN CARNÍVOROS SALVAJES BRASILEÑOS Y SUS IMPLICACIONES PARA LA CONSERVACIÓN Y LA SALUD PÚBLICA. Diversos brotes epidémicos causados por agentes patógenos han provocado una severa reducción de las poblaciones de carnívoros salvajes en las últimas décadas. Además de este impacto sobre las poblaciones silvestres, existe la preocupación de que haya transmisión de algunos de estos agentes a la población humana y de animales domésticos. De hecho, las alteraciones ambientales han provocado cambios en la relación patógeno-hospedero. De esta forma, el monitoreo de la salud de animales silvestres es un componente importante en el establecimiento de programas de control y erradicación de enfermedades y en la elaboración de políticas de salud pública y animal y de manejo y conservación de especies salvajes. Considerando el papel de los mamíferos del orden Carnivora en la cadena trófica, éstos pueden ser usados como "centinelas", siendo objetivos estratégicos en programas de vigilancia para detección de patógenos. Siendo así, en este artículo serán revisados estudios de caso de los principales patógenos que afectan a carnívoros salvajes, con énfasis en las especies de la fauna brasileña. Los métodos de laboratorio utilizados en los estudios de exposición de los carnívoros brasileños a patógenos serán discutidos así como consideraciones sobre estrategias para minimizar sus impactos sobre la fauna silvestre y los posibles métodos para el control de patógenos causantes de zoonosis en carnívoros.

Palabras clave: Orden Carnivora; medicina de la conservación; zoonosis; epidemiología; manejo de fauna.

\section{INTRODUÇÃO}

Em comparação com a perda de habitats, caça e poluição, a ocorrência de doenças pode parecer um problema menor para conservação de espécies selvagens. Entretanto, a ocorrência de patógenos pode afetar a abundância e distribuição de animais e nas últimas décadas o impacto das doenças nas populações de espécies selvagens de vida livre tem chamado a atenção de conservacionistas (p. ex. McCallum \& Dobson 1995, Murray et al. 1999, Woodroffe 1999, Cleaveland et al. 2007). Diversas espécies de carnívoros ameaçadas de extinção sofreram declínio de suas populações por epidemias causadas por doenças infecciosas, como nos surtos de cinomose em furões-de-patas-negras (Mustela nigripes Audubon \& Bachman 1851) (Thorne \& Williams 1988), em leões (Panthera Leo Linnaeus 1758) (Roelke-Parker et. al. 1996), em cachorros selvagens africanos (Lycaon pictus Temminck 1820) (Alexander et al. 1996) e de raiva em lobos da Etiópia (Canis simensis Rüppell 1840) (Sillero-Zubiri et al. 1996). Tais epidemias trouxeram a visão de que as doenças podem aumentar significativamente a mortalidade de animais selvagens de vida livre e levantaram a necessidade de integrar a epidemiologia na conservação e manejo de carnívoros selvagens.

Além do impacto que as doenças podem causar nas populações de animais selvagens, existe uma crescente preocupação com a transmissão de parasitas entre humanos, animais selvagens e domésticos. De fato, $61 \%$ de todos os patógenos humanos são classificados como zoonoses (Taylor et al. 2001) e cerca de $77 \%$ dos patógenos de animais de produção e $91 \%$ dos patógenos de carnívoros domésticos infectam múltiplos hospedeiros (Haydon et al. 2002). Desta forma, se estas infecções podem espalhar-se amplamente entre populações humanas depois de introduzidas (Ex: Influenza, HIV, Ebola) e podem "saltar" freqüentemente de animais reservatórios (Ex: raiva, brucelose, leptospirose), infecções zoonóticas podem ter um sério impacto sócio-econômico e de saúde coletiva. Os focos em animais silvestres de patógenos que acometem seres humanos e animais domésticos podem ameaçar a eficácia de programas nacionais e internacionais de controle e erradicação de doenças, implementados mediante alto investimento financeiro (Bengis et al. 2002). 
A maioria das recentes emergências de doenças infecciosas foi causada por mudanças nas interações ecológicas entre patógenos e hospedeiros (Dobson \& Carper 1996, Daszak et al. 2001). Tais mudanças podem ser naturais ou de origem antropogênica, incluindo expansão das atividades humanas e fronteiras agropecuárias, fragmentação de habitats, poluição, entre outras (Patz et al. 2000). Essas mudanças ecológicas permitem o aumento do contato entre espécies de patógenos e novas populações de hospedeiros e a seleção natural pressiona para a dominância de patógenos que se adaptem a essas novas condições ambientais (Daszak et al. 2001). Isso pode tornar cada vez mais comum a ocorrência de epidemias em animais selvagens causadas por parasitas provenientes de animais domésticos (Funk et al. 2001).

De um lado, populações de carnívoros selvagens podem sofrer com severas epizootias e declínios relacionados a doenças de animais domésticos. Do outro, espécies como raposas e coiotes, que são bem adaptadas a ambientes alterados, podem servir como fontes de infecção para humanos e animais domésticos (Aguirre 2009). Adicionalmente, a transmissão de patógenos entre animais domésticos e selvagens é ainda mais preocupante se estes estão em ambientes fragmentados, com baixa variabilidade genética e/ ou expostos a patógenos emergentes (McCallum \& Dobson 2002, Patz et al. 2004, Travis et al. 2006), situação comum para grande parte dos animais selvagens brasileiros. Esta interface entre a saúde de seres humanos, animais selvagens e domésticos, abordada nesta revisão, está inserida no conceito de Medicina da Conservação (Tabor 2002).

Outro aspecto relevante é que carnívoros podem agir como "bioacumuladores" de exposição à patógenos, visto que, por ocuparem o topo da rede trófica, o consumo de hospedeiros infectados resulta em altas taxas de infecção. Desta forma, algumas espécies de carnívoros podem ser utilizadas como sentinelas, sendo alvos estratégicos em programas de vigilância para a detecção de patógenos (Cleaveland et al. 2006a, Aguirre 2009). Uma das maiores contribuições de um programa eficiente de monitoramento de doenças em animais selvagens de vida livre é a detecção em estágios iniciais da ocorrência de doenças novas ou emergentes, algumas das quais podem ter sérias implicações zoonóticas e econômicas (Mörner et al. 2002).
Muitos outros fatores ecológicos e epidemiológicos podem influenciar a distribuição de infecções em uma população suscetível, mas o desafio para conservacionistas e agentes de saúde coletiva é identificar as condições que levam uma infecção a se espalhar antes que as epidemias aconteçam. Assim, o estudo de doenças em populações selvagens é fundamental para implementação de programas eficazes de controle e erradicação de doenças e na elaboração de políticas de saúde pública e animal e de manejo e conservação de espécies selvagens

Nesse artigo, estudos de caso dos principais patógenos que acometem carnívoros selvagens foram revisados, com ênfase nas espécies da fauna brasileira. Os métodos diagnósticos utilizados nos estudos de ocorrência de patógenos nos carnívoros brasileiros foram discutidos e foram feitas considerações sobre estratégias para minimizar os impactos da exposição da fauna selvagem a estes agentes, bem como os possíveis métodos para controle da circulação em carnívoros de patógenos causadores de zoonoses.

\section{VÍRUS DA CINOMOSE}

O vírus da cinomose é causador de doença multisistêmica, altamente contagiosa, com evolução aguda ou subaguda, produzindo quadro febril, podendo atingir os sistemas respiratório, gastro-intestinal e nervoso central (Appel \& Summers 1995). A cinomose é conhecida na Europa há pelo menos 200 anos (Williams 2001). Sua ocorrência foi descrita em carnívoros selvagens de vida livre aproximadamente na metade do século XX (Helmbolt \& Jungherr 1955). Ela ocorre em todas as famílias de carnívoros e está distribuída por todo o mundo.

A transmissão do vírus da cinomose ocorre principalmente através de aerossóis ou contato com secreções orais, respiratórias ou oculares contendo o agente. Animais com infecção subclínica podem eliminar o vírus (Appel 1987) e o período de eliminação pode atingir até 90 dias após a infecção (Greene \& Appel 1998). É necessário contato próximo entre os animais afetados e suscetíveis para que a transmissão ocorra, uma vez que o vírus é rapidamente inativado no ambiente pelos raios ultravioletas, calor e ressecamento. Portanto, populações densas de animais suscetíveis são necessárias para que uma epizootia ocorra em uma determinada região. Da mesma forma, o comportamento das espécies 
envolvidas também é fundamental na transmissão do vírus. Espécies gregárias e sociais tendem, portanto, a favorecer a transmissão, enquanto os animais solitários e territorialistas apresentam uma chance menor de transmitir ou contrair o vírus. Assim, diversos fatores são determinantes na epidemiologia da cinomose em uma determinada região, como a suscetibilidade dos hospedeiros, a densidade das populações de hospedeiros suscetíveis simpátricos e a existência de aspectos comportamentais que favoreçam o contato intra e interespecíficos e, portanto, a transmissão do agente (Williams 2001).

Os sinais clínicos decorrentes da cinomose dependem da espécie acometida, idade, estado imunológico, variante do vírus envolvida e condições ambientais (Williams 2001). Nos carnívoros selvagens, na maioria das vezes, os sintomas são variações daqueles apresentados pelos cães domésticos. Os sinais clínicos mais característicos nos cães são depressão, secreção mucopurulenta nasal e ocular, dermatites e hiperqueratose dos coxins, tosse e outras manifestações respiratórias, distúrbios gastroentéricos e neurológicos (incoordenação motora, mioclonia, rigidez muscular, ataxia, convulsões, paresia, paralisia, cegueira) (Greene \& Appel 1998).

Nos canídeos, os animais jovens parecem ser mais suscetíveis (Krakowka \& Koestner 1976). A mortalidade decorrente da infecção também é bastante variável entre as diferentes espécies (Williams 2001). Algumas espécies selvagens apresentam-se especialmente suscetíveis e o número de animais infectados que se recuperam é extremamente baixo, como é o caso de furões-de-patas-negras ( $M$. nigripes) (Williams et al. 1988) e raposas cinzentas (Urocyon cinereoargenteus Schreber 1775) (Davidson et al. 1992). Entre os cães domésticos, estima-se que 25 a $75 \%$ dos indivíduos infectados desenvolvem infecção subclínica e eliminam o vírus sem desenvolver a doença (Greene \& Appel 1998).

Em áreas enzoóticas, com grandes populações de cães domésticos, a doença clínica é observada principalmente em filhotes de três a seis meses, coincidindo com o período de queda dos anticorpos maternos. Em populações isoladas, o vírus da cinomose, quando é introduzido, costuma ocorrer de forma epidêmica, acometendo cães de todas as idades (Leighton et al. 1988).

Diversos surtos de cinomose foram relatados em carnívoros de vida livre na África e América do
Norte, alguns deles causando declínios populacionais significativos em decorrência de aumento da mortalidade. Nos Estados Unidos, um surto de cinomose atingiu aquela que era considerada, à época, a última colônia de furões-de-patas-negras (M. nigripes) na natureza, causando a morte de vários indivíduos (Williams et al. 1988). Naquela ocasião, a espécie passou a ser considerada extinta na natureza. Davidson et al. (1992) determinaram que o vírus foi responsável por $78 \%$ da mortalidade das raposas cinzentas ( $U$. cinereoargenteus) do sudeste norte-americano. Outra espécie sob risco de extinção bastante ameaçada por este patógeno é o cachorroselvagem-africano (L. pictus). O agente foi implicado como responsável por mortalidade expressiva de indivíduos da espécie em Botswana (Alexander et al. 1996) e Tanzânia (Van De Bildt et al. 2002), e pelo desaparecimento da espécie na Reserva de Masai Mara, no Quênia (Alexander \& Appel 1994). Neste mesmo Parque, $55 \%$ dos leões ( $P$. leo) testados foram considerados positivos à sorologia (Kock et al. 1998). No Serengeti, a cinomose causou a morte de cerca de $1 / 3$ da população de leões (RoelkeParker et al. 1996). Em alguns destes casos, cães domésticos foram identificados como sendo a origem mais provável do agente (Alexander \& Appel 1994, Roelke-Parker et al. 1996, Cleaveland et al. 2000). Diante dos surtos citados, devido ao significativo aumento de mortalidade causado pelo agente em populações de diversas espécies de carnívoros de vida livre, a cinomose é considerada como uma das doenças infecciosas que mais ameaça a conservação destes animais.

Para os mamíferos carnívoros da América do Sul, as publicações relacionadas à ocorrência da cinomose, ou mesmo exposição ao agente, ainda são escassas. Até o final do século XX, os estudos publicados com espécies sul-americanas se restringiam a relatos de casos ou levantamentos da ocorrência da doença em animais mantidos em cativeiro. Segundo Maia \& Gouveia (2002), entre 1989 e 1998, 9\% da mortalidade de lobos-guarás em cativeiro no Brasil foi atribuída às doenças infecciosas. Dentro deste grupo, a cinomose foi relacionada a $19,4 \%$ dos óbitos. Em um zoológico norte-americano, um surto de cinomose causou a morte de diversos felinos selvagens, dentre os quais uma onça-pintada (Panthera onca Linnaeus 1758) (Appel et al. 1994). Nos últimos 10 anos, no entanto, alguns estudos foram publicados com 
levantamentos sorológicos em carnívoros da fauna brasileira de vida livre. Courtenay et al. (2001) testaram cães domésticos de uma comunidade rural no Marajó (Pará) e cachorros-do-mato (Cerdocyon thous Linnaeus 1766) que frequentavam as casas dos vilarejos da região em busca de comida. Os cachorrosdo-mato ( $C$. thous) foram todos negativos enquanto os cães apresentaram positividade em dois dos 23 amostrados (9\%). No Parque Nacional Noel Kempf Mercado, na Bolívia, dois lobos-guarás (Chrysocyon brachyurus Illiger 1815) foram positivos à sorologia dentre quatro capturados (Deem \& Emmons 2005). Outro estudo na Bolívia detectou quatro graxainsdo-campo (Lycalopex gymnocercus G. Fischer 1814) positivos sorologicamente para a exposição ao vírus da cinomose dentre nove indivíduos capturados, enquanto os cinco cachorros-do-mato ( $C$. thous) amostrados na região foram negativos (Fiorello et al. 2007). Em Minas Gerais, Curi (2005) testou sorologicamente três lobos-guarás (C. brachyurus), nove cachorros-do-mato e duas raposas-do-campo (Lycalopex vetulus Lund 1842) capturados na região da Serra do Cipó. Todos foram considerados negativos. Cães domésticos amostrados na região tiveram $65,7 \%$ de positividade (46/70). No norte do Pantanal, Jorge (2008) testou 75 carnívoros para exposição ao vírus. Vinte e um foram positivos, dentre os quais 12 de 43 cachorros-do-mato (C. thous), três de oito lobos-guarás (C. brachyurus), dois de 13 mãos-peladas (Procyon cancrivorus Cuvier, 1798), um de sete pumas (Puma concolor Linnaeus, 1771) e três de quatro jaguatiricas (Leopardus pardalis Linnaeus 1758). Dentre os 69 cães domésticos amostrados na região, 56 foram positivos. Nava et al. (2009) diagnosticaram seis onças-pintadas ( $P$. onca) dentre 10 amostradas e um de sete pumas (P. concolor) positivas para a exposição no Parque Estadual de Ivinhema (Mato Grosso do Sul). Dentre os cães domésticos amostrados na região, todos foram considerados positivos $(\mathrm{n}=11)$. Neste mesmo estudo, foram amostradas nove onças-pintadas ( $P$. onca), dois pumas (P. concolor) e duas jaguatiricas (L. pardalis) no Parque Estadual do Morro do Diabo, oeste do estado de São Paulo, a cerca de 150 quilômetros do Parque Estadual de Ivinhema. Todos os animais foram negativos. Nesta região, 35 de 101 cães amostrados foram positivos.

Os resultados positivos ao sorodiagnóstico obtidos em carnívoros de vida livre na América do
Sul indicam que, em algumas regiões, estes animais foram expostos ao vírus da cinomose ou a um agente antigenicamente semelhante.

A cinomose é uma doença comum em cães domésticos no Brasil. É possível que em algumas das regiões sul-americanas estudadas o vírus da cinomose tenha sido transmitido inicialmente dos cães domésticos para os carnívoros selvagens, a exemplo do que foi sugerido em estudos realizados na África (Alexander \& Appel 1994, Roelke-Parker et al. 1996, Cleaveland et al. 2000). A grande proporção de animais positivos encontrada entre os cães domésticos na maioria dos levantamentos realizados em nosso continente reforça esta hipótese. O provável contato entre cães domésticos e carnívoros selvagens que utilizam áreas próximas às casas de moradores que residem em zona rural e periurbana é compatível com os resultados de Courtenay et al. (2001). Neste estudo, 22 cachorros-do-mato dentre os 24 aparelhados com rádios-colares visitaram vilas localizadas na região amazônica, no estado do Pará, demonstrando o alto potencial de contato entre os carnívoros domésticos e selvagens.

As características ecológicas dos carnívoros selvagens sul-americanos de médio e grande porte abrangidos nos estudos de exposição ao vírus da cinomose são, de forma geral, pouco favoráveis à transmissão do agente. Os carnívoros da nossa fauna são geralmente solitários, territorialistas e ocorrem em baixas densidades populacionais. Estas características são desfavoráveis ao contato direto entre os indivíduos, que seria um fator predisponente para a transmissão deste vírus (Williams 2001). No entanto, se considerarmos a comunidade de carnívoros como um todo e não as densidades das espécies de forma isolada, podemos vislumbrar a possibilidade de uma cadeia de transmissão capaz de manter a circulação do vírus no ambiente silvestre. Vale ressaltar que algumas espécies constituem-se como exceções ao padrão dos carnívoros brasileiros, como é o caso dos cachorros-do-mato (C. thous), que geralmente são observados em pares reprodutivos, ou mesmo em pequenos grupos familiares, formados pelo casal e filhotes ou juvenis, e ocorrem em densidades mais altas. Desta forma, a espécie poderia se comportar como um reservatório regional do vírus da cinomose, com episódios eventuais de transmissão para indivíduos de outras espécies, a exemplo do que foi sugerido para a espécie em relação à raiva na 
região Nordeste (Carnieli et al. 2008). Outras duas exceções são cachorros vinagres (Speothos venaticus Lund 1842) e quatis (Nasua nasua Linnaeus 1766), que são espécies gregárias.

\section{PARVOVÍRUS}

Os vírus pertencentes ao grupo dos parvovírus infectam e podem causar quadro clínico em uma grande parte das espécies de carnívoros selvagens. Este grupo inclui o Parvovírus felino (FPV), o Parvovírus canino (CPV), o vírus da enterite dos visões (MEV), o vírus da doença Aleutiana dos visões e o Parvovírus dos guaxinins (Cleaveland et al. 2006b). Apesar das diferentes espécies de parvovírus terem sido batizadas de acordo com os hospedeiros nos quais elas ocorrem mais comumente, esta nomenclatura pode causar confusão no entendimento de sua epidemiologia. O FPV, por exemplo, pode eventualmente infectar canídeos, assim como o CPV pode infectar felídeos (Barker \& Parrish 2001).

O parvovírus felino é reconhecido por causar a panleucopenia felina desde a primeira metade do século XX. Estudos realizados nas décadas de 1930 e 1940 revelam que diversas síndromes descritas em gatos domésticos naquela época com denominações variadas eram na realidade causadas por este agente (Parrish 1990). Naquele período, o FPV também foi implicado na mortalidade de felídeos selvagens em cativeiro (Hyslop 1955).

Em 1978 duas novas síndromes começaram a ser observadas com freqüência em cães domésticos. Uma delas era caracterizada como uma miocardite em filhotes abaixo dos quatro meses de idade e a outra como uma gastroenterite em animais de todas as idades. Os primeiros casos parecem ter ocorrido na Europa, mas rapidamente se espalharam pelo mundo todo (Parrish 1990). Robinson et al. (1980) identificaram um parvovírus como agente causador de ambas as síndromes. Este passou a ser conhecido como parvovírus canino tipo 2 , como forma de diferenciá-lo do Vírus minuto canino (Pollock \& Carmichael 1990). No entanto, este nome passou a ser preterido e o vírus passou a ser chamado de parvovírus canino (Barker \& Parrish 2001). O vírus também atingiu os canídeos selvagens em um curto espaço de tempo. Já em 1979 foram detectados anticorpos em coiotes (Canis latrans Say 1823) nos Estados Unidos e até 1981 a maioria dos animais desta espécie em Texas, Idaho e Utah eram soropositivos (Thomas et al. 1984).

O CPV provavelmente derivou do FPV ou de um vírus intimamente relacionado (Truyen et al. 1996). Apesar das seqüências de DNA dos isolados de CPV e FPV terem uma identidade de superior a 98\%, eles podem ser distinguidos através de anticorpos monoclonais (Parrish \& Carmichael 1983) e pela diferença de $\mathrm{pH}$ e temperatura característicos para a ocorrência de hemaglutinação (Carmichael et al. 1980, Senda et al. 1988). O encontro de seqüências de DNA intermediárias entre as dos dois vírus a partir de tecidos de raposas vermelhas (Vulpes vulpes Linnaeus 1758) na Europa sugere que animais selvagens podem ter tido grande importância no processo de transmissão do FPV aos cães domésticos (Truyen et al. 1998).

Os parvovírus são bastante resistentes no ambiente. Quando protegidos da incidência direta dos raios solares, de altas temperaturas e ressecamento, podem permanecer viáveis por meses (Gordon \& Angrick 1986). Quando comparados com outros agentes virais, como os vírus da raiva e da cinomose, têm um período de infectividade relativamente longo e uma vez introduzidos em uma região, tendem a persistir. Devido a estas características, os parvovírus tendem a ocorrer de forma endêmica nas regiões de ocorrência (Cleaveland et al. 2006b).

A idade dos animais acometidos tem grande importância na patogenia, pois os parvovírus necessitam de células em divisão para sua replicação. Animais jovens têm grandes quantidades de células em divisão e tecidos como o miocárdio e o cérebro são freqüentemente afetados. Nos animais adultos, as células do epitélio intestinal e tecidos linfáticos são geralmente as mais afetadas. Conseqüentemente, os animais desta faixa etária costumam apresentar gastroenterite, linfopenia e leucopenia (Steinel et al. 2001).

O possível incremento na mortalidade de filhotes é citado em diversos estudos como o principal problema que pode ser causado pelos parvovírus em populações de carnívoros selvagens. Em uma população de lobos (Canis lupus Linnaeus 1758) de Minnesota (EUA) amostrada e monitorada entre 1979 e 1990, percebeuse que, em anos onde a prevalência para o CPV dos animais amostrados era mais alta, a proporção de 
filhotes capturados era menor e, no ano subseqüente, observava-se uma diminuição na taxa de aumento da população (Mech \& Goyal 1993). Outro estudo com a mesma espécie realizado em Montana (EUA) observou que nas matilhas de lobos onde ocorreu mortalidade de filhotes, os títulos dos indivíduos adultos amostrados eram altos para anticorpos para o CPV e para o vírus da cinomose, enquanto nas matilhas que conseguiram criar seus filhotes, os títulos de anticorpos para estes agentes eram baixos (Johnson et al. 1994). Para o cachorro-selvagemafricano (L. pictus), Creel et al. (1997) observaram que o número de filhotes nas ninhadas era menor nas regiões em que a prevalência para anticorpos para o $\mathrm{CPV}$ era mais alta.

Em relação aos carnívoros selvagens da fauna brasileira, existem registros em zoológicos de doença atribuída ao CPV em lobos-guarás ( $C$. brachyurus) (Fletcher et al. 1979, Mann et al. 1980, Maia \& Gouveia 2002), em cachorros-do-mato ( $C$. thous) (Mann et al. 1980) e em cachorros-vinagres (S. venaticus) (Janssen et al. 1982). Nos últimos anos, alguns estudos foram publicados com levantamentos sorológicos em animais de vida livre no Brasil e na Bolívia. Courtenay et al. (2001) testaram para a exposição ao parvovírus cães domésticos de uma comunidade rural no Pará e cachorros-do-mato (C. thous) que freqüentavam as casas dos vilarejos da região em busca de comida. Os cachorros-domato (C. thous) foram todos negativos enquanto os cães apresentaram positividade em três dos 23 amostrados (13\%). No Parque Nacional Noel Kempf Mercado, na Bolívia, quatro lobos-guarás (C. brachyurus) capturados e sorologicamente testados foram positivos, resultando em $100 \%$ de positividade na amostra (Deem \& Emmons 2005). Também na Bolívia, quatro cachorros-do-mato (C. thous) dentre cinco capturados e cinco entre nove graxains-do-campo (L. gymnocercus), foram considerados positivos ao sorodiagnóstico (Fiorello et al. 2007). Em Minas Gerais, Curi (2005) testou sorologicamente três lobos-guarás (C. brachyurus), nove cachorros-do-mato (C. thous) e duas raposasdo-campo (L. vetulus), capturados na região da Serra do Cipó. Todos foram considerados positivos. Cães domésticos amostrados na região tiveram 58,6\% de positividade (41/70). Filoni et al. (2006) realizaram um levantamento da exposição de felídeos selvagens de vida livre ao FPV. Foram analisadas amostras de soro de 21 animais de diversas regiões do Brasil, entre eles 18 pumas ( $P$. concolor), dois gatos-domato-pequenos (Leopardus tigrinus Schreber 1775) e uma jaguatirica (L. pardalis). Dez deles foram positivos à sorologia, sendo oito onças-pardas, um gato-do-mato-pequeno e uma jaguatirica. No norte do Pantanal, Jorge (2008) testou 76 carnívoros para exposição ao CPV. Setenta foram positivos, dentre os quais 42 de 43 cachorros-do-mato (C. thous), sete de oito lobos-guarás (C. brachyurus), 10 de 13 mãos-peladas ( $P$. cancrivorous) sete de sete pumas (P. concolor), três de quatro jaguatiricas (L. pardalis) e um de um cachorro-vinagre ( $S$. venaticus). Cães domésticos da região também foram testados. Dentre os 102 animais amostrados, 98 foram positivos.

À exceção do estudo realizado no Marajó (Courtenay et al. 2001), todos os outros levantamentos realizados em carnívoros brasileiros de vida livre diagnosticaram indivíduos positivos para a exposição aos parvovírus, em alguns casos em proporções bastante elevadas. Estes resultados não chegam a ser surpreendentes considerando os resultados positivos em cães domésticos em todas as regiões amostradas, assim como a característica deste grupo de vírus de ter considerável resistência no ambiente (Gordon \& Angrick 1986), favorecendo sua persistência nos locais onde é introduzido (Cleaveland et al. 2006b). No entanto, eles indicam a necessidade de aprofundamento nos estudos para buscar elucidar se a transmissão deste patógeno está aumentando a mortalidade das populações de carnívoros nas regiões amostradas.

\section{VÍRUS DA RAIVA}

A raiva é uma das mais antigas enfermidades infectocontagiosas descritas. Mesopotâmia e Egito conheciam sua presença na antiguidade e a relacionavam com a mordida de cães "loucos" (Megid 2007). Em 500 a.C. Democritus descreveu a doença em animais domésticos (Sikes 1972). O vírus da raiva afeta o Sistema Nervoso Central (SNC) de todas as espécies de mamíferos, porém são considerados como reservatório apenas as espécies de importância regional para a manutenção do agente (Rupprecht et al. 2001). O agente ocasiona um quadro de encefalite aguda e acarreta níveis de mortalidade elevados 
(Rupprecht et al. 2001, Megid 2007). Representa um sério problema de saúde pública na América Latina, África e Ásia.

$O$ vírus da raiva pertence à família Rhabdoviridade, ao gênero Lyssavirus, que apresenta sete genótipos diferentes e dois novos Lyssavirus ainda não classificados. É transmitido pela saliva de mamíferos terrestres e quirópteros infectados nos episódios de mordedura (Megid 2007).

$\mathrm{O}$ vírus rábico genótipo tipo 1 é um RNA-vírus negativo, que penetra nos miócitos onde pode replicarse e permanecer por tempo variável (Storts 1990), o que determina os diferentes períodos de incubação. Desloca-se por fusos musculares e tendíneos até os neurônios periféricos, passa por gânglios das raízes dorsais e medula, até atingir o cérebro. Este deslocamento é chamado de disseminação centrípeta (Storts 1990). A replicação viral se inicia nas vesículas citoplasmáticas, ocorre nos ribossomos livres e se completa no retículo endoplasmático rugoso e complexo de Golgi (Megid 2007). Esta replicação origina corpúsculos de inclusão intracitoplasmáticos, os corpúsculos de Negri, achado microscópico característico da raiva (Storts 1990). Após sua replicação no $\mathrm{SNC}$, o vírus rábico se espalha para diferentes tecidos através de nervos periféricos e atinge as glândulas salivares onde fica disponível para transmissão e a eliminação, que ocorre durante um curto período, concomitante ao aparecimento de sinais clínicos, ou pode se iniciar alguns dias antes do óbito do hospedeiro, que ocorre geralmente em poucos dias (Storts 1990, Rupprecht et al. 2001, Carter \& Wise 2005, Whelan 2009).

A doença apresenta distribuição mundial, excetuando-se regiões geograficamente isoladas (p.ex. ilhas do Reino Unido, Nova Zelândia e Japão) que não apresentam o genótipo tipo 1 segundo a Organização Mundial da Saúde. O vírus possui um ciclo urbano, mais fácil de controlar, e outro silvestre, que contribui para circulação e reintrodução do vírus (Childs 2002). A compreensão da raiva nos animais silvestres depende do entendimento da relação agentehospedeiro-ambiente (Wandeler 1993), incluindo a interação vírus-hospedeiro (susceptibilidade, infecção), a história natural dos hospedeiros (Rupprecht et al. 2001), as modificações ambientais provocadas pelo homem, ou mesmo a introdução do agente em áreas originalmente livres por transporte de indivíduos portadores.
A introdução da raiva pode trazer graves conseqüências a populações de carnívoros selvagens, principalmenteàquelas pequenas e isoladas (Gascoyne et al.1993) como ocorreu com a população de lobosda-etiópia (C. simensis) durante um surto da doença (Laurenson et al. 1997, Sillero-Zubiri et al. 1996). $\mathrm{O}$ agente continuou representando uma ameaça importante para a espécie nos anos subseqüentes (Randall et al. 2006). Os lobos cinzentos (C. lupus) (Weiler 1995) e os cachorros-selvagens-africanos (Kat et al. 1996, Hofmeyer et al. 2000) também tiveram declínio populacional decorrente da doença.

Na Europa e América do Norte, o bem sucedido controle da doença nos animais domésticos transferiu para as populações silvestres o papel de principais transmissores da doença nas últimas décadas, principalmente o guaxinim norte-americano (Procyon lotor Linnaeus 1758), o cangambá (Mephitis mephitis Schreber 1776) (Megid 2007), a raposa-vermelha ( $V$. vulpes) (Smith \& Baer 1988, Wandeler et al. 1988) e a raposa-cinzenta (U. cinereoargenteus) (Toma \& Andral 1977). Nas regiões árticas e subárticas do Canadá e do Alaska, a raiva é endêmica na raposado-ártico (Vulpes lagopus Linnaeus 1758), havendo relatos de transmissão para populações de lobos cinzentos (C. lupus) (Laurenson et al. 1997). Na América Latina, com o controle da doença nos cães, é provável que a raiva silvestre, mantida em uma variedade de hospedeiros mamíferos, também aumente de importância (Bernardi et al. 2005).

No Brasil, o ciclo urbano tem o cão como seu principal reservatório, e o ciclo silvestre os morcegos hematófagos. No entanto, estudos nos últimos dez anos têm detectado casos de raiva em morcegos não hematófagos, canídeos silvestres e sagüis (Brasil 2006). Na região Nordeste a raiva apresenta transmissão entre canídeos silvestres e seres humanos, assim como entre animais domésticossilvetres-domésticos (Carnieli et al. 2006, 2008), com o cachorro-do-mato (C. thous) como principal reservatório dentre as espécies de canídeos silvestres da região (Carnieli et al. 2008). Neste estudo, foi identificado um ciclo independente da raiva nestes animais na região. Aparentemente, o agente foi transmitido originalmente por cães domésticos aos silvestres, mas os resultados demonstram diferenças genéticas entre os isolados do vírus provenientes de cada um dos grupos em questão. Um fato preocupante é que esses animais são comumente criados como 
animais de estimação na região (Gomes 2004, Bernardi et al. 2005).

No Mato Grosso, Jorge (2008) encontrou anticorpos neutralizantes no soro de um puma $(P$. concolor), um cachorro-do-mato (C. thous), um mãopelada ( $P$. cancrivorous), e um cachorro-vinagre $(S$. venaticus). Em levantamento realizado nos biomas Cerrado e Pantanal em cinco localidades, 26 de 211 carnívoros selvagens amostrados foram considerados positivos ao sorodiagnóstico, sendo 13 de 91 lobos guarás capturados (C. brachyurus), quatro de 69 cachorros-do-mato (C. thous), um de um cachorrovinagre $(S$. venaticus), três de 13 onças pintadas $(P$. onca), duas de 10 jaguatiricas (L. pardalis), 1 de 8 pumas ( $P$. concolor), um de cinco gatos palheiros (Leopardus colocolo Molina 1782) e um de 13 mãospeladas (P. cancrivorous) (Jorge et al. no prelo). Nas demais regiões do país, informações sobre a exposição dos canídeos silvestres são insuficientes ou inexistentes.

Os dados de literatura sobre a exposição de carnívoros selvagens de vida livre ao vírus da raiva em diversas partes do planeta aqui mencionados demonstram que estes animais podem representar reservatórios importantes do agente regionalmente, como também podem ter sua sobrevivência ameaçada por ele. É possível constatar também que, no Brasil, apesar de os esforços do Ministério da Saúde no controle da raiva ainda estarem voltados principalmente à vacinação dos cães domésticos, a preocupação com a circulação do vírus rábico em animais silvestres tem aumentado significativamente. O diagnóstico de um ciclo do vírus da raiva em canídeos silvestres na região Nordeste do país deve ser tratado com bastante atenção. Estudos suplementares sobre a circulação do vírus em animais silvestres no Brasil devem ser incentivados e medidas voltadas ao controle da ocorrência do agente na fauna silvestre devem começar a ser planejadas e testadas, com base nas ações adotadas com sucesso na Europa e América do Norte, como, por exemplo, a vacinação oral.

\section{LEPTOSPIRA SPP.}

Grupo de espiroquetas patogênicas causadoras da leptospirose com mais de 170 sorovares organizados em 19 sorogrupos (Roth 1972, Nielsen et al. 1989). A leptospirose é uma zoonose cosmopolita (Corrêa e
Passos 2001) que acomete a maioria dos mamíferos (Thiermann 1984). Estes podem se tornar portadores, contribuindo assim para disseminação do agente. Ocorre no meio urbano, rural e silvestre, de forma epidêmica ou endêmica, dependendo das interações de fatores ambientais e dos diferentes grupos animais hospedeiros (Vasconcellos 1987). Os sinais clínicos mais observados são espasmos musculares, incoordenação, icterícia, hemoglobinúria, febre, perda de peso, vômitos, podendo levar à morte (Horsh 1999, Levett 2001).

Mamíferos com alta susceptibilidade para infecção, sem sintomatologia clínica ou com forma branda podem ser considerados reservatórios (Leighton \& Kiuken 2001). A Leptospira spp. se aloja nos rins (Correa \& Passos 2001) e é eliminada pela urina dos portadores por poucas semanas ou vários meses entre os animais domésticos, e por toda vida no caso dos roedores (Webster et al. 1995). Os animais se contaminam através da pele íntegra (imersa por longo período na água) e mucosas, assim como pela ingestão por água e alimentos contaminados (Levett 2001, Corrêa 2007).

Levantamentos sorológicos em carnívoros selvagens de cativeiro no Brasil demonstram níveis significativos de exposição em canídeos e felídeos (Guerra-Neto et al. 2004, Corrêa et al. 2004).

Ao testar através de diagnóstico sorológico diversas espécies de mamíferos capturados no estado do Tocantins, Souza Júnior et al. (2002) detectaram quatro dentre 31 quatis ( $N$. nasua) e dois dentre 10 cachorros-do-mato (C.thous) positivos, mas sem sinais clínicos no momento da captura. Jorge (2008) testou 75 carnívoros selvagens capturados em uma reserva no Pantanal do Mato Grosso e 32 foram considerados positivos para exposição (17 de 43 cachorros-domato $C$. thous testados, três de oito lobos-guará $C$. brachyurus, um de um cachorro-vinagre $S$. venaticus, seis de 12 mãos-peladas $P$. Cancrivorous, dois de sete pumas $P$. concolor e três de quatro jaguatiricas (L. pardalis). Os cachorros-do-mato (C.thous) foram a espécie mais intensamente amostrada e, portanto, aquela cuja frequência encontrada deve ser a mais próxima da prevalência real. A proporção de indivíduos da espécie sorologicamente positivos foi bastante considerável (40\%). O resultado encontrado em mãos-peladas ( $P$. cancrivorous) é importante por se tratar de espécie filogeneticamente próxima ao 
guaxinim norte-americano ( $P$. lotor), considerado reservatório nos EUA (Mitchell 1999). A detecção de indivíduos positivos em todas as espécies de carnívoros selvagens amostradas no norte do Pantanal (Jorge 2008) indica que a cadeia epidemiológica da leptospirose é bastante complexa na região.

O maior impacto nas populações de mamíferos selvagens tem sido os registros de abortamento e perdas reprodutivas (Roth 1972). No entanto, o real papel dos carnívoros no ciclo da leptospirose e o impacto desta nas populações de vida livre, ainda são desconhecidos.

\section{LEISHMANIA SPP.}

As leishmanioses, complexo de doenças causadas por parasitas do gênero Leishmania, são consideradas reemergentes em algumas regiões e emergentes em outras e constituem um grave problema de saúde coletiva. Atualmente, são endêmicas em 88 países e mais de 350 milhões de pessoas estão em risco, com incidência estimada em dois milhões de novos casos por ano (Desjeux 2004).

Na América Latina, as espécies de Leishmania causam duas doenças com diferentes formas clínicas nos seres humanos: a leishmaniose visceral americana (LVA), que é fatal se não tratada, e a leishmaniose tegumentar americana (LTA), que inclui as formas cutânea, cutâneo-mucosa ou cutâneo-difusa, que podem causar severas lesões mutilantes. A transmissão ocorre pela picada de insetos de fêmeas de diferentes espécies de flebotomíneos (Diptera: Phlebotominae), conhecidos popularmente, como mosquito palha e birigui, entre outros (Brasil 2007).

No Brasil, a LVA predomina na região nordeste, mas vem se expandindo para o restante do país, com média anual de 3.156 casos nos últimos dez anos (Brasil 2003). Sua transmissão vem sendo descrita em vários municípios, de todas as regiões do país, inclusive na região Sul, considerada livre da doença até 2008 (Souza et al. 2009). A LTA é uma zoonose amplamente distribuída no território brasileiro, ocorrendo em todas as regiões do país. Segundo o Ministério da Saúde, a média anual de casos autóctones entre os anos de 1985 e 2005 foi de 28.568 , sendo que entre 1988 e 2005 o número de casos por ano oscilou entre 20.000 e 36.000 (Brasil 2007).
Os reservatórios primários de Leishmania spp. são mamíferos selvagens de diversas ordens, especialmente roedores e canídeos selvagens (Ashford 2000, Dantas-Torres 2007, Beck et al. 2008). Contudo, com o crescente aumento do processo de domiciliação do ciclo zoonótico de transmissão das leishmanioses, cães domésticos têm assumido importante papel como reservatórios da infecção, sendo fundamentais na transmissão para humanos (Moreno \& Alvar 2002, Dantas-Torres 2007).

No Velho Mundo, inquéritos sorológicos reportaram a presença de Leishmania spp. em diversas espécies de carnívoros selvagens, como em raposas vermelhas ( $V$. vulpes) em Portugal (SemiãoSantos et al. 1996), Itália (Mancianti et al. 1994), Espanha (Fisa et al. 1999; Portús et al. 2002) e Israel Central (Baneth et al. 1998) e em chacais (Canis aureus Linnaeus 1758) no Iran, Iraque, Israel Central e Cazaquistão (Baneth et al. 1998, Mohebali et al. 2005).

Estudos utilizando diagnóstico por reação de polimerase em cadeia (PCR) reportaram prevalências de 4\% nas raposas ( $V$. vulpes) da Espanha Central (Criado-Fornalio et al. 2000) e 40\% no sul da Itália (Dipineto et al. 2007). No Iran, um lobo (C. lupus) foi positivo (Mohebali et al. 2005). Mais recentemente, Sobrino et al. (2008) detectaram o DNA do parasita em amostras de sangue ou baço em 16,2\% dos carnívoros selvagens da Espanha analisados, incluindo oito dos 39 (20,5\%) lobos-cinzentos (C. lupus) testados, 23 das $162(14,1 \%)$ raposas (V. vulpes), dois dos 7 sete (28,6\%) mangustos egípicios (Herpestes ichneumon Linnaeus 1758), 1 dos 4 genetas (Genetta genetta Linnaeus 1758) e um dos quatro lince-Ibéricos (Lynx pardinus Temminck 1827). Na Croácia, pesquisadores encontraram um lobo-cinzento (C. lupus) morto com lesões características de leishmaniose visceral canina. As análises patológicas e parasitológicas confirmadas por PCR indicaram que as lesões eram associadas a $L$. infantum e os pesquisadores sugeriram que este era o primeiro relato de morte de um lobo-cinzento devido a lesões causadas por L. infantum (Beck et al. 2008).

No Brasil, estudos pioneiros de Deane e Deane (1954) descreveram os primeiros relatos de infecção natural por Leishmania spp. em raposa-do-campo (L. vetulus) e seu possível papel como reservatório. Entretanto, Courtenay et al. (1996) demonstraram, através de estudos comparativos de morfologia 
cranial e dental e distribuição geográfica, que os espécimes encontrados por Deane e Deane no Ceará foram erroneamente identificados e concluíram que o canídeo silvestre envolvido era o cachorro-domato (C. thous), questionando o papel das raposasdo-campo (L. vetulus) como reservatório naquela ocasião.

Cachorros-do-mato (C. thous) têm sido considerados por diversos autores como potenciais fontes de infecção por LVA para humanos por demonstrarem altas prevalências (em alguns casos, acima de 42\%) de infecção parasitologicamente confirmadas (Deane \& Deane, 1955, Silveira et al. 1982, Lainson et al. 1990, Courtenay et al. 1994) e terem altas taxas de contato com cães infectados e com o principal vetor $\mathrm{Lu}$. longipalpis (Courtenay et al. 2001).

Outros estudos relatam a exposição à Leishmania spp. em carnívoros silvestres de vida livre. Curi et al. (2006) reportaram a prevalência de anticorpos antiLeishmania em canídeos silvestres da Serra do Cipó, Minas Gerais. Dos 21 animais analisados, dois lobosguarás (C. brachyurus) e dois cachorros-do-mato $(C$. thous) foram positivos. Mais recentemente, no Estado do Paraná, dois cachorros-do-mato, duas raposas-docampo, um quati ( $N$. nasua) e um mão-pelada $(P$. cancrivorous) foram positivos no inquérito sorológico realizado por Voltarelli et al. (2009). No Norte do Pantanal, através de técnicas moleculares, espécimes de lobo-guará, cachorro-do-mato, mão-pelada e jaguatirica (L. pardalis) foram diagnosticados como naturalmente expostos a Leishmania braziliensis (Jorge 2008).

Em carnívoros silvestres mantidos em cativeiro, Figueiredo et al. (2008) diagnosticaram infecção natural por Leishmania (Leishmania) chagasi em um cachorro-vinagre ( $S$. venaticus) capturado na natureza no Mato Grosso e mantido em cativeiro na Fundação Jardim Zoológico do Rio de Janeiro. Outros dois cachorros-vinagres apresentaram sinais clínicos de leishmaniose no Centro de Conservação da Fauna silvestre em Ilha Solteira, SP (Lima et al. 2009). Ambos foram positivos no teste de ELISA e apresentaram formas amastigotas do parasita em esfregaços de linfonodo. Amostras de tecido de um deles foram avaliadas por PCR e os pesquisadores detectaram DNA de Leishmania spp. nas amostras de fígado e linfonodo, entretanto os testes foram negativos nas amostras de baço e pele. Após piora do quadro clínico, ambos os indivíduos vieram a óbito (L. Souza, comunicação pessoal). Luppi et al. (2008) reportaram sorologia positiva para cachorrodo-mato (C. thous), lobo-guará (C. brachyurus), raposa-do-campo ( $L$. vetulus) e cachorro-vinagre $(S$. venaticus) do zoológico de Belo Horizonte, Minas Gerais. Destes, um cachorro-vinagre (S. venaticus) e uma raposa-do-campo (L. vetulus) desenvolveram sinais clínicos. O primeiro veio a óbito e o segundo foi eutanasiado devido à sua péssima condição clínica e prognóstico. Na necropsia, ambos apresentaram lesões características de leishmaniose visceral confirmadas por diagnóstico histopatológico e imunohistoquímico. Dahroug et al. (2010) reportaram ainda a infecção por $L$. (L.) chagasi em cinco pumas ( $P$. concolor) e uma onça-pintada (P. onca).

Os estudos citados demonstram o possível envolvimento dos carnívoros selvagens na epidemiologia das leishmanioses. Contudo, é necessário um aprofundamento maior para esclarecer os papéis desempenhados pelas diferentes espécies de carnívoros silvestres na epidemiologia das leishmanioses nas diversas regiões de sua ocorrência. Ainda, o potencial impacto das diferentes espécies de Leishmania sobre as populações de carnívoros selvagens é pouco conhecido.

Outro aspecto importante a ser considerado diz respeito ao crescente aumento do contato entre espécies selvagens e domésticas e ao intercâmbio de espécimes entre zoológicos. Embora a população de canídeos silvestres seja insignificante quando comparada à de cães domésticos, a translocação de animais infectados de um zoológico para outro pode eventualmente levar à disseminação da doença (Figueiredo et al. 2008, Luppi et al.2008). Este contato pode ainda resultar em novas áreas endêmicas, visto que novos casos humanos podem se originar a partir da expansão de um foco residual (Ashford 1996).

Em relação às medidas de controle, o programa brasileiro de controle da leishmaniose visceral (Brasil 2003) se baseia no tratamento dos casos humanos, controle do vetor pelo uso de inseticidas e controle de reservatório canino (inquérito sorológico de cães e eutanásia de cães soropositivos). No caso de animais de cativeiro, medidas como uso permanente de coleiras impregnadas com deltametrina e controle químico por borrifação de piretróide a cada três meses 
devem ser adotadas em áreas endêmicas (Luppi et al. 2008). Em animais silvestres infectados, várias questões devem ser consideradas antes de se optar pela eutanásia, visto que algumas espécies são ameaçadas de extinção como o lobo-guará e o cachorro-vinagre e não existe informação suficiente sobre o potencial de transmissão das diversas espécies de carnívoros brasileiros. Desta forma, entender o papel que os carnívoros silvestres desempenham na manutenção e expansão dos ciclos de transmissão de Leishmania spp. é essencial na definição de medidas efetivas de controle dessa parasitose.

\section{ECTOPARASITAS}

Pertencentes à classe Arachnida e ordem Acarina (Allan 2001), os carrapatos são um dos mais importantes grupos de ectoparasitas de vertebrados terrestres, voadores e semi-aquáticos em todos os continentes do mundo, inclusive Antártida (Labruna et al. 2005). Alimentam-se de sangue e fluidos tissulares, causam perturbação e alterações como anemia, lesões cutâneas e hipersensibilidade (Hargis 1990), embora o principal papel epidemiológico seja como vetor de uma grande variedade de agentes patogênicos (Allan 2001).

Populações de animais na natureza são reguladas por fatores abióticos e bióticos. Dentre estes estão os parasitas (Borgsteede 1996). Hospedeiros e parasitas evoluíram em paralelo ao longo de milhares de anos e diferentes carrapatos dependem da presença de uma ou mais espécies de hospedeiro para desenvolver o ciclo biológico completo (Grenfell \& Gulland 1995, Poulin 1997, Labruna et al. 2005).

Com a fragmentação do ambiente, as extinções locais de mamíferos selvagens têm ocorrido de maneira cada vez mais frequente (Fahrig \& Merriam 1994) e, portanto, muitos carrapatos têm tido dificuldade para desenvolver seu ciclo biológico nos hospedeiros específicos, o que os faz procurar novas espécies para completar o ciclo, criando novas relações hospedeiroparasita (Poulin 1997). Estas novas relações podem acarretar debilidade ao novo hospedeiro, podendo inclusive levá-lo a óbito (Borgsteede 1996).

Os carrapatos geralmente passam $90 \%$ de seu ciclo fora do hospedeiro, o que os torna vulneráveis a modificações ambientais. O estudo das espécies de carrapatos dos carnívoros pode indicar escalas de alteração ambiental em determinadas áreas (Labruna et al. 2005). O estudo evolutivo de parasitas ajuda a compreender seu papel na dinâmica das populações de seus hospedeiros (Grenfell \& Gulland 1995), uma vez que eles podem representar uma ameaça às pequenas populações vulneráveis de animais selvagens de vida livre (Cleveland et al. 2003) pela transmissão de patógenos.

A extensa área de vida que os carnívoros geralmente possuem (Emmons 1999) e o contato com diversas espécies de presas (Oliveira 1994) aumentam o risco de infestação por diferentes gêneros de carrapatos (Labruna et al. 2005). Alterações ambientais, principalmente por influência humana, podem também proporcionar contato com novas espécies (Borgsteede 1996).

Carrapatos alimentam-se em uma grande variedade de vertebrados domésticos e silvestres (Randolph et al. 2003), podendo transmitir entre os hospedeiros diversos patógenos, como, por exemplo, Babesia spp., Borrelia burgdorferi, Francisella tularensis, Rickettsia spp. e Cytauxzoon felis (Röken 1993). No entanto, a presença de carrapatos nos hospedeiros nem sempre é correlacionada com a presença de hemoparasitas. Babesia spp. e Ehrlichia spp. são encontrados em guaxinins norte-americanos (P. lotor) (Comer et al. 2000), mas não há registros em procionídeos na América do Sul (Gomes-Solecki 2001).

Labruna et al. (2005) descrevem as espécies de carrapatos que já foram encontradas parasitando carnívoros, sendo o gênero Amblyomma o mais encontrado: Amblyomma ovale (14 espécies), Amblyomma cajenennense(10 espécies), Amblyomma aureolatum (10 espécies), Amblyomma tigrinum (sete espécies), Amblyomma parvum (sete espécies). Rhipicephalus (Boophilus) microplus foi encontrado em sete espécies de carnívoros. Esta espécie de carrapato tem o gado como hospedeiro primário, o que indica a presença dos carnívoros utilizando áreas de pastagem de bovinos.

Os ácaros são da mesma classe e ordem dos carrapatos, mas apresentam seu ciclo biológico na epiderme de mamíferos. Entre 1994 e 1996, em populações de quatis (Nasua narica Linnaeus 1766) na região oeste do México, Notoedres cati causou epizootia com maior impacto nas populações com menor grau de isolamento e áreas mais fragmentadas 
pela influência humana (Valenzuela et al. 2000). Em populações de coiotes (C. latrans) monitoradas entre 1974 e 1991 no sudeste do estado do Texas, nos Estados Unidos, a sarna sarcóptica (Sarcoptes scabei) foi diagnosticada inicialmente em 1975 e teve um pico em 1980, com $69 \%$ dos animais infectados, tendo decrescido até 1991(Pence \& Windberg 1994). O maior impacto foi na redução da ovulação e prenhez das fêmeas. Foi observada alta taxa de infecção nos machos adultos.

No Brasil, estudos sobre a presença e impacto das sarnas nas diferentes espécies de mamíferos são escassos. Jorge et al. (2008) capturaram um casal de cachorros-vinagres (S. venaticus) em Nova Xavantina (MT). Ambos os animais apresentavam rarefação pilosa. Foram equipados com rádios-colares e monitorados por rádio-telemetria. Após três meses, o macho veio a óbito. A fêmea foi recapturada para realização de raspados de pele. Após o diagnóstico de S. scabiei, a fêmea foi tratada através de duas aplicações do antiparasitário selamectina, com 35 dias de intervalo. $\mathrm{O}$ tratamento apresentou bons resultados. Relatos de moradores que observaram canídeos silvestres na região apresentando alopecia, além do monitoramento de outro grupo de cachorrosvinagres no qual os animais apresentaram alopecia e vieram a óbito sem, no entanto, ter sido realizado o diagnóstico (E.S. Lima, resultados não publicados), reforçam o potencial impacto da sarna sarcóptica na população desta espécie na região de Nova Xavantina.

\section{CONSIDERAÇÕES SOBRE MÉTODOS DIAGNÓSTICOS}

Os estudos de exposição de carnívoros selvagens de vida livre a patógenos realizados na América do Sul envolveram principalmente levantamentos por sorodiagnóstico. À exceção do estudo de exposição ao vírus da raiva na região Nordeste (Bernardi et al. 2005, Carnieli et al. 2006, 2008) e do relato de sarna sarcóptica em cachorros-vinagres (Jorge et al. 2008), nenhum dos trabalhos realizados em nosso continente possibilitou detectar objetivamente morbidade ou mortalidade em decorrência da exposição a patógenos. Portanto, é necessário o incentivo à realização de estudos que busquem elucidar se de fato esta exposição está ameaçando a viabilidade das populações de carnívoros selvagens da fauna brasileira ou mesmo interferindo de alguma forma na sua estrutura.

Neste sentido, estudos com animais de cativeiro são importantes, pois possibilitam acompanhar a evolução clínica, mortalidade e o possível impacto de determinados patógenos na saúde dos animais silvestres, o que seria muito difícil de ser realizado em indivíduos ou populações de vida livre. Alguns exemplos importantes são a observação de que o vírus da cinomose pode causar mortalidade em onças pintadas P. onca (Appel et al. 1994) e o desenvolvimento de sinais clínicos seguido de morte por leishmaniose visceral em canídeos silvestres mantidos em cativeiro (Luppi et al. 2008).

Da mesma forma, estudos envolvendo infecção experimental também podem elucidar aspectos da relação entre patógeno e hospedeiro que apenas podem ser explorados através do controle dos diversos fatores que envolvem um processo infeccioso. Herrera et al. (2001, 2002), por exemplo, observaram a resposta clínica, humoral e parasitológica de quatis experimentalmente infectados por Trypanosoma evansi e concluíram que a persistente parasitemia e a relativa tolerância dos quatis aos sinais clínicos da doença sugerem que esta espécie desenvolve uma doença crônica e tem importante papel na epidemiologia da mesma em áreas endêmicas. Courtenay et al. (2002) expuseram cachorros-domato (C. thous) capturados no Marajó, Pará (alguns deles diagnosticados posteriormente como expostos à L. chagasi), assim como cães domésticos da mesma região, a espécimes do vetor criados em cativeiro. Os autores observaram que os canídeos selvagens não infectaram os vetores, diferentemente dos domésticos. Desta forma, eles inferem que a espécie, a mais estudada dentre os canídeos selvagens com relação à exposição à $L$. chagasi e frequentemente citada como potencial reservatório silvestre do agente, não teria grande importância na transmissão do agente por sua baixa infectividade para o vetor. Tais estudos demonstram como trabalhos com infecção experimental podem esclarecer aspectos do efeito e da patogenia do patógeno no hospedeiro, assim como aspectos epidemiológicos, como o papel de uma determinada espécie silvestre no ciclo de transmissão de um agente patogênico.

As técnicas moleculares vêm tendo papel fundamental e devem ser cada vez mais utilizadas 
nos levantamentos futuros e mesmo naqueles já realizados, mas que colheram e armazenaram material para análises posteriores. Elas têm a vantagem de, em alguns casos, possibilitar determinar quais agentes estão de fato sendo transmitidos dos animais domésticos para os selvagens e quais estão circulando e sendo mantidos pelos animais selvagens, podendo, eventualmente ser transmitidos aos domésticos e aos seres humanos. Um exemplo interessante são os estudos de Carnieli et al. (2006, 2008), que demonstraram que o vírus da raiva tem circulado entre os canídeos silvestres há algum tempo, e que estes animais vêm mantendo um ciclo do agente independente dos animais domésticos. Outro exemplo é o estudo de Biek et al. (2006) que descreveram detalhes da estrutura populacional e recente história demográfica da população de pumas ( $P$. concolor $)$ de Rocky Mountains (EUA) através do estudo das linhagens genéticas dos vírus da Imunodeficiência Felina (FIV) que acometiam esses animais. Segundo os autores, o uso de ferramentas moleculares, especialmente com patógenos de transmissão direta e evolução rápida, pode trazer informações substanciais sobre características espaciais e temporais do contato entre hospedeiros.

Por outro lado, as técnicas de diagnóstico sorológico têm uma grande importância por detectarem anticorpos produzidos para o combate aos patógenos, possibilitando que, mesmo que o agente já não circule no organismo do animal nem esteja sendo eliminado, seja possível encontrar indícios indiretos de sua circulação. Ainda assim, é importante destacar que estas técnicas apresentam o inconveniente de não diagnosticarem animais positivos no início da infecção, quando apesar de estar infectado, o organismo ainda não produziu uma quantidade de anticorpos passível de ser detectada. Adicionalmente, estas técnicas também têm a limitação de sofrer a influência de reações inespecíficas e possíveis reações cruzadas com patógenos antigenicamente relacionados e, como são desenvolvidas para animais domésticos, é necessário cautela para se decidir os pontos de corte utilizados para as espécies silvestres. Um ponto de corte muito baixo pode gerar resultados enganosos, considerando como expostos indivíduos que na realidade não o foram, enquanto um ponto de corte muito alto pode desconsiderar a exposição dos animais a um patógeno que de fato circula entre eles.
Na realidade, o ideal para estudos que procuram pesquisar a exposição de animais selvagens a agentes patogênicos é a realização, sempre que possível, tanto de métodos moleculares, como sorológicos e parasitológicos, aliados ao exame clínico e exames complementares, como hemograma e bioquímica sérica. Vale ressaltar que o diagnóstico de uma espécie ou indivíduo infectado não define sua importância na cadeia de transmissão, especialmente considerandose que as redes de transmissão de patógenos flutuam no tempo e no espaço. A interpretação dos resultados depende de diversos fatores, como características ecológicas das espécies de hospedeiros na região estudada, local de amostragem dos animais, evolução da infecção nos indivíduos amostrados, suas variações e aspectos relacionados, entre outros, na tentativa de se criar um cenário da transmissão e assim inferir os possíveis riscos e definir as estratégias de controle.

$O$ fato é que apenas estudos multidisciplinares de longo prazo, envolvendo aspectos ecológicos e monitoramento de populações de forma contínua, aliados à pesquisa da ocorrência de patógenos, procurando determinar relações entre estes fatores, poderão determinar de forma efetiva a importância de agentes infecciosos e parasitários para a conservação dos carnívoros selvagens da fauna brasileira, assim como sua importância no ciclo epidemiológico de agentes que afetam o homem e animais domésticos.

\section{ESTRATÉGIAS DE MANEJO E MEDIDAS DE CONTROLE}

O controle de patógenos frequentemente presentes em animais domésticos que podem infectar e ameaçar populações de animais selvagens pode ser focado na implementação de medidas voltadas à redução da incidência do agente nos animais domésticos de uma determinada região, daquelas direcionadas diretamente aos animais selvagens, como também pode estar voltada para a limitação do contato entre estes dois grupos (Laurenson et al. 2005).

Para reduzir as interações entre animais domésticos e carnívoros selvagens seria necessário limitar fisicamente o contato entre eles. Isto poderia hipoteticamente ser realizado através da implementação de uma zona tampão ao redor de áreas protegidas, onde fosse proibida a presença de animais domésticos. No entanto, certamente haveria 
uma enorme resistência dos moradores do entorno destas áreas.

A alternativa aparentemente mais viável para diminuir o potencial impacto de doenças infecciosas na população de carnívoros selvagens de vida livre é o controle dos agentes em animais domésticos, especialmente nos cães. Para isto, é necessário implementar campanhas anuais de vacinação para as doenças de interesse nos animais domésticos das comunidades que residem no entorno de áreas protegidas, de forma continuada. Entretanto, para que um programa de vacinação seja bem sucedido, é importante que algumas medidas complementares sejam realizadas de forma concomitante. A realização de vacinação em massa de cães domésticos em uma determinada região sem a implementação de um programa de controle populacional, por exemplo, pode acarretar em aumento significativo da população, devido à retirada de um fator que provavelmente tem um papel importante no controle demográfico dos cães. Neste cenário, caso a vacinação seja suspensa após algum tempo, a quantidade de animais suscetíveis passará a ser ainda maior do que aquela existente no momento anterior à sua implementação. Desta forma, caso um patógeno seja introduzido nesta nova população hipotética, causará uma epizootia ainda mais intensa do que as ocorridas anteriormente (Woodroffe 1999, Woodroffe et al. 2004). Assim, implementar concomitantemente à vacinação técnicas para o controle da população de cães nestas comunidades, como a realização de campanhas de castração e campanhas educativas de posse responsável, é fundamental para o sucesso dessa estratégia.

A vacinação de cães domésticos tem ainda a vantagem de poder abranger tanto agentes infecciosos de interesse para a conservação de animais selvagens como aqueles de importância em Saúde Pública e animais de criação. Desta forma, a vacinação pode envolver uma cooperação entre instituições com interesses diversos, como governo, associações de criadores, conservacionistas, entre outros, possibilitando a divisão de custos e tarefas.

Outra possibilidade de intervenção são as medidas de controle de patógenos implementadas diretamente nas populações de carnívoros selvagens de vida livre. Algumas opções são: a vacinação direta dos carnívoros selvagens, a diminuição da densidade de populações de espécies consideradas como reservatórios de patógenos que acometem o homem ou animais domésticos através da eutanásia, ou o tratamento de indivíduos infectados.

Em relação à vacinação direta dos carnívoros selvagens, um exemplo importante é a realização de vacinação anti-rábica oral de canídeos silvestres na Europa e América do Norte que vem sendo realizada há vários anos, permitindo um sucesso significativo no controle da doença nestes continentes (Cross et al. 2007). Esta iniciativa foi implementada com o intuito de diminuir o número de animais suscetíveis, interrompendo a transmissão do vírus entre os indivíduos das espécies consideradas como reservatórios regionais do agente (principalmente a raposa vermelha, $V$. vulpes), com o objetivo de atingir um problema de Saúde Pública que ocorria nestas regiões. É possível que no Brasil intervenção semelhante seja necessária na região Nordeste do país, uma vez que o $C$. thous já foi identificado como reservatório regional da raiva (Carnieli et al. 2008). Por outro lado, este tipo de abordagem, quando realizado com vistas à conservação de carnívoros selvagens, ocorreu apenas em ocasiões isoladas, em situações emergenciais, sem utilizar uma metodologia que permitisse avaliar sua efetividade, como, por exemplo, comparações entre grupos vacinados e controle. Portanto, ainda necessita muita discussão e experimentação para poder provar sua efetividade (Woodroffe 1999, Laurenson et al. 2005).

Muitas vacinas utilizam na sua composição agentes vivos atenuados para uma espécie doméstica, como o cão, e por ocasião de sua aplicação em uma espécie selvagem filogeneticamente próxima, podem causar a doença e mesmo o óbito do animal vacinado. Por outro lado, não é certo que a aplicação de uma vacina desenvolvida para outra espécie resulte na imunidade desejada, especialmente caso seja aplicada em dose única, como deve ocorrer com freqüência em programas de vacinação parenteral em animais selvagens.

Outro método historicamente utilizado para o controle da circulação de patógenos em animais silvestres com o intuito de diminuir a ocorrência de uma determinada doença de interesse para o ser humano é a eliminação de indivíduos da espécie considerada como reservatório, através da eutanásia. Este visa reduzir a população de indivíduos suscetíveis 
da espécie alvo abaixo de um determinado nível, fazendo, desta forma, com que se torne impossível ao patógeno manter-se circulando nestas condições (Cross et al. 2007).

No entanto, esta estratégia de manejo apresenta alguns argumentos contrários à sua utilização. Um deles está relacionado à sua viabilidade financeira. Frequentemente, o resultado da redução da incidência de um patógeno obtido ao se eliminar animais silvestres, não justifica os recursos financeiros gastos (Cross et al. 2007). Muitas vezes, os mecanismos ecológicos de regulação das populações de algumas espécies de animais silvestres fazem com que, após algum tempo, o número de indivíduos suscetíveis passe a ser equivalente ao momento anterior ao início da utilização desta medida, ou ainda mais elevado. Outro argumento desfavorável é a possibilidade de impacto ecológico sobre espécies consideradas ameaçadas de extinção. Neste caso a utilização deste tipo de abordagem é totalmente inaceitável, e, em muitos países, é também ilegal.

$\mathrm{Na}$ Europa e América do Norte, a redução da população de carnívoros selvagens de médio porte foi amplamente utilizada até aproximadamente 1975 com o intuito de controlar a transmissão do vírus da raiva aos seres humanos por estes animais. Entretanto, o método apresentou resultados pouco efetivos e sua relação custo-benefício demonstrouse amplamente desfavorável. Durante o período de sua utilização ocorreu um espalhamento geográfico das regiões enzoóticas. Apenas reduções transitórias nos níveis de incidência da doença foram observadas (Aubert 1999). Diante destes resultados, a eliminação de carnívoros selvagens passou a ser substituída ao longo da década de 1970 por programas de vacinação oral em larga escala, metodologia que se mostrou amplamente eficaz no controle da doença.

A eutanásia dos texugos (Meles meles Linnaeus 1758) no Reino Unido para controle do Mycobacterium bovis, agente causador da tuberculose bovina tem sido um componente da política de controle da tuberculose no Reino Unido por três décadas. Entre 1975 e 1997 mais de 20 mil texugos foram eutanasiados (Donnelly et al. 2003). Apesar dos esforços, a incidência de tuberculose nos bovinos tem aumentado consistentemente e reemergido como uma das principais preocupações da indústria pecuária européia. Experimentos de campo em larga escala demonstraram que essa estratégia pode causar tanto o aumento quando a diminuição da incidência de tuberculose em bovinos, visto que a eutanásia dos texugos reduz a incidência de tuberculose nos bovinos localmente, mas aumenta a incidência nas áreas adjacentes especialmente em locais onde a paisagem permite que os texugos recolonizem novas áreas (Donnelly et al. 2003, 2006).

Outra alternativa para o controle da circulação de patógenos em carnívoros selvagens é o tratamento de animais infectados. O tratamento clínico de infecções virais em carnívoros selvagens raramente é possível, mas existem casos de programas que obtiveram sucesso em tratamento de surtos com infecções bacterianas e com macro e ectoparasitas (Woodroffe 1999). Valenzuela et al. (2000), por exemplo, combinaram estratégias de tratamento de animais com acaricidas e eutanásia, dependendo da severidade da infecção nos indivíduos, para conter um surto de sarna em quatis-do-focinho-branco $(N$. narica).

Apesar das diversas opções de intervenções expostas, a necessidade de se intervir em populações de animais selvagens de vida livre deve sempre ser avaliada com cautela. Artois (2003) recomenda que os pesquisadores envolvidos nesta área do conhecimento devem comparar a evolução esperada de uma infecção na presença e ausência de uma estratégia de controle e exemplifica casos em que uma intervenção inadequada pode diminuir a dispersão natural da doença, aumentando o período de duração de suas conseqüências (Smith \& Harris 1991, Tischendorf et al. 1998).

É importante que ocorra uma ampla discussão entre pesquisadores e órgãos do governo como os Ministérios do Meio Ambiente, da Saúde e da Agricultura, Pecuária e Abastecimento, assim como as autarquias e centros de referência a eles vinculados, sobre as estratégias de manejo e medidas de controle aqui mencionadas para que protocolos seguros sejam elaborados e testados, possibilitando sua utilização com base em resultados obtidos com o rigor científico necessário.

\section{CONSIDERAÇÕES FINAIS}

Como podemos constatar em estudos realizados recentemente no Brasil e nos países vizinhos, 
carnívoros selvagens de vida livre são expostos a patógenos que comumente causam morbidade e mortalidade em animais domésticos e que, historicamente, já causaram mortalidade em carnívoros de vida livre em outros continentes. Isto demonstra a importância de se levar em consideração a circulação de patógenos na elaboração dos planos de manejo das Unidades de Conservação (UCs), como também reforça a necessidade da implementação das zonas de amortecimento (faixa no entorno das UCs que visa diminuir o impacto das atividades antrópicas sobre a biota por ela protegida, Brasil, 2000) para áreas destinadas à proteção da fauna, inclusive com a implementação de medidas voltadas para o controle de patógenos em animais domésticos nestas áreas.

Os carnívoros selvagens são expostos também a agentes que causam agravos no homem e em animais domésticos. Apesar dos resultados de estudos apontarem para a possibilidade destes animais agirem como reservatórios para enfermidades como as leishmanioses, a raiva e a leptospirose, é necessário que se avalie de forma mais aprofundada o real papel deste grupo taxonômico no ciclo epidemiológico destas doenças, realizando estudos que determinem se eles são importantes na transmissão destes agentes.

Ao longo desta revisão, pudemos notar que a quantidade de informações a respeito da exposição dos carnívoros selvagens da fauna brasileira a agentes infecciosos e parasitários tem aumentado consideravelmente nos últimos anos. Estamos nos aproximando de um patamar onde os dados produzidos permitirão embasar a formulação de medidas de manejo efetivas para a conservação dos carnívoros selvagens sul-americanos como também para o controle da circulação de patógenos de importância em Saúde Pública. Evidentemente, os estudos envolvendo levantamentos de exposição a patógenos continuam, e continuarão por muito tempo, tendo grande relevância em nosso continente, pois ainda há muitas espécies de hospedeiros, microrganismos $\mathrm{e}$ regiões a serem contemplados. Mas é importante que os pesquisadores que atuam nesta área tenham sempre como objetivo final a aplicação destes conhecimentos para o planejamento do controle da circulação de patógenos de importância para a conservação da biodiversidade e para a Saúde Pública.

\section{REFERÊNCIAS}

AGUIRRE, A.A. 2009. Wild canids as sentinels of ecological health: a conservation medicine perspective. Parasites \& Vectors, 2: S7.

ALEXANDER, K.A. \& APPEL, M.J.G. 1994. African wild dogs (Lycaon pictus) endangered by a canine distemper epizootic among domestic dogs near the Masai Mara National Reserve, Kenya. Journal of Wildlife Diseases, 30: 481-485.

ALEXANDER, K.A.; KAT, P.W.; MUNSON, L.A.; KALAKE, A. \& APPEL, M.J.G. 1996. Canine distemper-related mortality among wild dogs (Lycaon pictus) in Chobe National Park, Botswana. Journal of Zoo Wildlife Medicine, 27: 426-27.

ALLAN, S.A. 2001. Ticks (Class Arachnida: Ordem Acarina). Pp. 72-106. In: W.M. Samuel, M.J. Pybs \& A.A. Kocan. (eds.). Parasitic Diseases of Wild Mammals. Iowa State University Press. 536p.

APPEL, M.J.G. \& SUMMERS, B.A. 1995. Pathogenicity of morbilliviruses for terrestrial carnivores. Veterinary Microbiology, 44: 187-191.

APPEL, M.J.G. 1987. Canine distemper virus. Pp: 133-159. In: M.J.G. Appel (ed.). Virus infections of carnivores. Elsevier Science, Amsterdam. 516p.

APPEL, M.J.G.; YATES, R.A.; FOLEY, G.L.; BERNSTEIN, J.J.; SANTINELLI, S.; SPELMAN, L. H.; MILER, L.D.; ARP, L.H.; ANDERSON, M.; BARR, M.; PEARCE-KELLING, S. \& SUMMERS, B.A. 1994. Canine distemper enzootic in lions, tigers, and leopards in North America. Journal Veterinary Diagnostic Investigation, 6(3): 277-288.

ARTOIS, M. 2003. Wildlife infectious disease control in Europe. Journal Mountain Ecology, 7 (supplement): 89-97.

ASHFORD, R.W. 1996. Leishmaniasis reservoirs and their significance in control. Clinics in Dermatology, 14: 523-532.

ASHFORD, R.W. 2000. The leishmaniases as emerging and reemerging zoonoses. International Journal for Parasitology, 30 : 1269-1281.

AUBERT, M.F. 1999. Costs and benefits of rabies control in wildlife in France. Revue Scientifique et Technique de l'Office International des Épizooties, 18: 533-43.

BANETH, G.; DANK, G.; KEREN-KORNBLATT, E.; SEKELES, E.; ADINI, I.; EISENBERGER, C.L.; SCHNUR, L.F.; KING, R. \& JAFFE, C.L. 1998. Emergence of visceral leishmaniasis in central Israel. The American journal of tropical medicine and hygiene, 59: 722-725. 
BARKER, I.K. \& PARRISH, C.R. 2001. Parvovirus Infections. Pp. 3-36. In: E.S. Williams \& I.K. Barker (eds.). Infectious diseases of wild mammals. ( $3^{\mathrm{a}}$ edição). Iowa State University Press, Ames. 302p.

BECK, A.; BECK, R.; KUSAK, J.; GUDAN, A.; MARTINKOVIC, F.; ARTUKOVIC, B.; HOHSTETER, M.; HUBER, D.; MARINCULIC, A. \& GRABAREVIC, Z. 2008. A Case of Visceral Leishmaniasis in a Gray Wolf (Canis lupus) from Croatia. Journal of Wildlife Diseases, 44: 451-456.

BENGIS, R.G., KOCK, R.A. \& FISCHER, J. 2002. Infectious animal diseases: the wildlife/livestock interface. Revue Scientifique et Technique de l'Office International des Épizooties, 21: 53-65.

BERNARDI, F.; NADIN-DAVIS, S.A.; WANDELER, A.I.; ARMSTRONG, J.; GOMES, A.A.B.; LIMA, F.S.; NOGUEIRA, F.R.B. \& ITO, F. H. 2005. Antigenic and genetic characterization of rabies viruses isolated from domestic and wild animals of Brazil identifies the hoary fox as a rabies reservoir. Journal of General Virology, 86: 3153-3162.

BIEK, ROMAN, ALEXEI J DRUMMON \& MARY POSS. 2006. A virus reveals population structure and recent demographic history of its carnivore host. Science, 311 (5760): 538-41.

BORGSTEEDE, F.H.M. 1996. The Effect of Parasites on Wildlife. The Veterinary Quaterly, 18: S138- S140.

BRASIL. 2000. Poder Executivo. Lei $n^{\circ} 9.985$ de 18 de julho de 2000. Regulamenta o art. $225, \S 1^{\circ}$, incisos I, II, III, e VII da Constituição Federal, institui o Sistema Nacional de Unidades de Conservação da Natureza e dá outras providências. Diário Oficial da União, Brasília, 19/07/2000. <http://www6.senado.gov.br/ legislacao/ListaNormas.action?numero=009985\&tipo_norma $=\mathrm{L}$ EI\&data $=20000718 \&$ link $=\mathrm{s}>$. (Acesso em: 19/02/2008).

BRASIL. 2003. Ministério da Saúde. Manual de vigilância e controle da Leishmaniose Visceral Brasília: Ministério da Saúde.122p.

BRASIL. 2006. Ministério da Saúde. Doenças transmissíveis: raiva humana. $<\mathrm{http}: / /$ portal.saude.gov.br/portal/svs/visualizar_ texto.cfm?idtxt=21906>. (Acesso em: 07/12/2009).

BRASIL. Ministério da Saúde. 2007. Manual de vigilância da Leishmaniose tegumentar americana. 2a edição. Brasília: Ministério da Saúde. 182p.

CARMICHAEL, L.E.; JOUBERT, J.C.; POLLOCK, R.V.H. 1980. Hemagglutination by canine parvovirus: serologic studies and diagnostic applications. American Journal of Veterinary Research, 41(5): 784-791.

CARNIELI, P.; BRANDAO,P.E.; CARRIERI, M.L.; CASTILHO, J.G.; MACEDO, C.I.; MACHADO, L.M.; RANGEL, N.; CARVALHO, R.C.; CARVALHO, V.A.; MONTEBELLO, L.; WADA, M. \& KOTAIT I. 2006. Molecular epidemiology of rabies virus strains isolated from wild canids in Northeastern Brazil. Virus Research, 120: 113-120.

CARNIELI, P.; FAHL, W.O.; CASTILHO, J.G.; OLIVEIRA, R.N.O; MACEDO, C.I.M.; DURYMANOVA, E.; JORGE, R.S.P.; MORATO, R.G.; SPINDOLA, R.O.; MACHADO, L.M.; SA, J.E.U.; CARRIERI, M.L.; KOTAIT, I. 2008. Characterization of Rabies virus isolated from canids and identification of the main wild canid host in Northeastern Brazil. Virus Research, 131: 33-46.

CARTER G.R. \& WISE D.J. 2005. Rhaboviridae. International Veterinary Information Service. $<$ http://www.ivis.org/ advances/carter/Part2Chap19/chapter.asp?LA=1>. (Acesso em 20/01/2010).

CHILDS, J. 2002. Epidemiology. Pp. 113-161. In: A. C. Jackson \& W.H. Wunner (eds.). Rabies. Academic Press, San Diego. 493p.

CLEAVELAND, S.; APPEL, M.G.J.; CHALMERS, W.S.K.; CHILlINGWORTH, C.; KAARE, M.; DYE, C. 2000. Serological and Demographic evidence for domestic dog as a source of canine distemper virus infection for Serengeti wildlife. Veterinary Microbiology, 72: 217-227.

CLEAVELAND, S.; HESS, G.H.; DOBSON, A.P.; LAURENSON, M.K.; McCALLUM, H.I.; ROBERTS, M.G. \& WOODROFFE, R. 2003. The role of pathogens in Biological Conservation. Pp. 139-150. In: P.J. Hudson, A. Rizzoli, B.T. Grenfell, H. Heesherbeek \& A.P. Dobson. The Ecology of Wildlife Diseases. Oxford University Press. 218p.

CLEAVELAND, S.; MESLIN, F.X. \& BREIMAN, R. 2006a. Dogs can play useful role as sentinel hosts for disease. Nature, 440: 605 .

CLEAVELAND, S.; LAURENSON, K.; FUNK, S.; PACKER, C. 2006b. Impact of viral infections in wild carnivore populations. Pp. 326-349. In: R.G. Morato; F.H.G. Rodrigues; E. Eizirik; P.R. Mangini; F.C.C. Azevedo \& J. Marinho-Filho (orgs.). Manejo e conservação de carnívoros neotropicais. IBAMA, São Paulo. $396 \mathrm{p}$.

CLEAVELAND, S.; MLENGEYA, T.; KAARE, M.; HAYDON, D.; LEMBO, T.; LAURENSON, M.K. \& PACKER, C. 2007. 
The conservation relevance of epidemiological research into carnivore viral diseases in the serengeti. Conservation Biology, 21: 612-622.

COMER, J.A.; NICHOLSON, W.L.; PADDOCK, C.D.; SUMMER, J.W. \& CHILDS, J.E. 2000. Detection of Antibodies Reactive with Ehrlichia chaffeensis in the raccoon. Journal of Wildlife Diseases, 36: 705-712.

CORRÊA, S.H.R. 2007. Leptospirose. Pp. 736-741. In: Z.S. Cubas, J.C.R. Silva \& J.L. Catão-Dias (eds. ou orgs.?). Tratado de Animais Selvagens, Medicina Veterinária. Roca, São Paulo. 1354p.CORRÊA, S.H.R. \& PASSOS, E.C. 2001. Wild Animals and Public Health. Pp. 493-499 In: M.E. FOWLER \& Z.S. CUBAS. (eds.) Biology, Medicine, and Surgery of South American Wild Animals. Iowa State Universiy Press. 536p.

CORRÊA, S.H.R.; VASCONCELLOS, S.A. \& MORAIS, Z. 2004. Epidemiologia da Leptospirose em animais silvestres na Fundação Parque Zoológico de São Paulo. Brazilian Journal of Veterinary Research and Animal Sciences, 41: 189-193.

COURTENAY, O.; MACDONALD, D.W.; LAINSON, R.; SHAW, J.J. \& DYE, C. 1994. Epidemiology of canine leishmaniasis: a comparative serological study of dogs and foxes in Amazon Brazil. Parasitology, 109: 273-279.

COURTENAY, O.; QUINNELL, R. J.; GARCEZ, L.M. \& DYE, C. 2002. Low infectiousness of a wildlife host of Leishmania infantum: the crab-eating fox is not important for transmission. Parasitology, 125: 407-414.

COURTENAY, O.; QUINNELL, R.J. \& CHALMERS, W.S.K. 2001. Contact rates between wild and domestic canids: no evidence of parvovirus or canine distemper virus in crab-eating foxes. Veterinary microbiology, 81: 9-19.

COURTENAY, O.; SANTANA, E.W.; JOHNSON, P.J.; VASCONCELOS, I.A.B. \& VASCONCELOS, A.W. 1996. Visceral leishmaniasis in the hoary zorro Dusicyon vetulus: a case of mistaken identity. Transactions of the Royal Society of Tropical Medicine and Hygiene, 90: 498-502.

CREEL, S.; CREEL, N.M.; MUNSON, L.; SANDERLIN, D. \& APPEL, M.J. 1997. Serosurvey for selected viral diseases and demography of African wild dogs in Tanzania. Journal of Wildlife Diseases, 33: 823-832.

CRIADO-FORNALIO, A.; GUTIERREZ-GARCIA, L.; RODRIGUEZ-CAABEIRO, F.; REUS-GARCIA, E.; ROLDANSORIANO, M.A. \& DIAZ-SANCHEZ, M.A. 2000. A parasitological survey of wild red foxes (Vulpes vulpes) from the province of Guadalajara, Spain. Veterinary Parasitololgy, 92: 245-251.

CROSS, M.L.; BUDDLE, B.M. \& ALDWELL, F.E. 2007. The potential of oral vaccines for disease control in wildlife species. The Veterinary Journal, 174: 472-480.

CURI, N. 2005 Avaliação do estado de saúde e do risco de transmissão de doenças entre canídeos (Mammalia, Carnívora) silvestres e domésticos na região da Serra do Cipó, Minas Gerais: implicações para a conservação. Dissertação de mestrado. Programa de pós-graduação em zoologia de vertebrados. Pontifícia Universidade Católica de Minas Gerais, Belo Horizonte, Brasil. 101p.

CURI, N.H.A.; MIRANDA, I. \& TALAMONI, S.A. 2006. Serologic evidence of leishmania infection in free-ranging wild and domestic canids around a Brazilian national park. Memórias do Instituto Oswaldo Cruz, 101: 99-101.

DAHROUG, M.A.A.; ALMEIDA, A.B.P.F.; SOUSA, V.R.F.; DUTRA, V.; TURBINO, N.C.M.R; NAKAZATO, L. \& SOUZA, R.L. 2010. Leishmania (Leishmania) chagasi in captive wild felids in Brazil. Transactions of the Royal Society of Tropical Medicine and Hygiene, 104: 73-74.

DANTAS-TORRES, F. 2007. The role of dogs as reservoirs of Leishmania parasites, with emphasis on Leishmania (Leishmania) infantum and Leishmania (Viannia) braziliensis. Veterinary Parasitology, 149: 139-146

DASZAK, P.; CUNNINGHAM, A.A. \& HYATT, A.D. 2001. Anthropogenic environmental change and the emergence of infectious diseases in wildlife. Acta Tropica, 78: 103-116.

DAVIDSON, W.R.; NETTLES, V.F.; HAYES, L.E.; HOWERTH, E.W. \& COUVILLION, C.E. 1992. Diseases diagnosed in gray foxes (Urocyon cinereoargentateus) from the southeastern United States. Journal of Wildlife Diseases, 28: 28-33.

DEANE, L.M. \& DEANE, M.P. 1954. Encontro de leishmanias nas vísceras e na pele de uma raposa, em zona endêmica de calazar, nos arredores de Sobral, Ceará. Hospital, 45: 419-421.

DEANE, L.M. \& DEANE, M.P. 1955. Observações preliminares sobre a importância comparativa do homem, do cão e da raposa (Lycalopex vetulus) como reservatórios da Leishmania donovani em área endêmica de calazar no Ceará. Hospital, 48: 61-76.

DEEM, S.L. \& EMMONS, L.H. 2005. Exposure of free-ranging maned wolves (Chrysocyon brachyurus) to infectious and 
parasitic disease agents in the Noël Kempff Mercado National Park, Bolivia. Journal of Zoo and Wildlife Medicine, 36: 192-197.

DESJEUX, P. 2004. Leishmaniasis: current situation and new perspectives. Comparative Immunology Microbiology \& Infectious Disease, 27: 305-318.

DIPINETO, L.; MANNA, L.; BAIANO, A.; GALA, M.; FIORETTI, A.; GRAVINO, A.E. \& MENNA, L.F. 2007. Presence of Leishmania infantum in red foxes (Vulpes vulpes) in southern Italy. Journal of Wildlife Diseases, 43:518-520.

DOBSON, A.P. \& CARPER, E.R. 1996. Infectious diseases and human population history. Bioscience, 46: 115-126.

DONNELLY, C.A.; WOODROFFE, R.; COX, D.R.; BOURNE, F.J.; CHEESEMAN, C.L.; CLIFTON-HADLEY, R.S.; WEI, G.; GETTINBY, G.; GILKS, P.; JENKINS, H.; JOHNSTON, W.T.; LE FEVRE, A.M.; MCINERNEY, J.P. \& MORRISON, W.I. 2006. Positive and negative effects of widespread badger culling on tuberculosis in cattle. Nature, 439: 843-846.

DONNELLY, C.A.; WOODROFFE, R.; COX, D.R.; BOURNE, J.; GEORGE GETTINBY, G.; LE FEVRE, A.M.; MCINERNEY, J.P. \& MORRISON, W.I. 2003. Impact of localized badger culling on tuberculosis incidence in British cattle. Nature, 426: 834-837.

EMMONS, L.H. 1999. Neotropical Rainforest Mammals, a field guide. $2^{\mathrm{a}}$ edição. The University of Chicago Press. 146p.

FAHRIG, L. \& MERRIAM, G. 1994. Conservation of Fragmented Populations. Conservation Biology, 8: 50-59.

FIGUEIREDO, F.B.; GREMIÃO, I.D.; PEREIRA, S.A.; FEDULO, L.P; MENEZES, R.C.; BALTHAZAR, D.A., SCHUBACHA, T.M.P. \& MADEIRA, M.F. 2008. First report of natural infection of a bush dog (Speothos venaticus) with Leishmania (Leishmania) chagasi in Brazil. Transactions of the Royal Society of Tropical Medicine and Hygiene, 102: 200-201.

FILONI, C.; CATÃO-DIAS, J.L.; BAY, G.; DURIGON, E.L.; JORGE, R.S.P.; LUTZ, H. \& HOFMANN-LEHMANN, R. 2006. First Evidence of Feline Herpesvirus, Calicivirus, Parvovirus, and Ehrlichia Exposure in Brazilian Free-ranging Felids. Journal of Wildlife Diseases, 42: 470-477.

FIORELLO, C.V.; NOSS, A.J.; DEEM, S.L.; MAFFEI, L. \& DUBOVI, E.J. 2007. Serorurvey of small carnivores in the Bolivian Chaco. Journal of Wildife Diseases, 43: 551-557.

FISA, R.; GÁllego, M.; CASTILleJO, S.; AISA, M. J.; SERRA, T.; RIERA, C.; CARRIÓ, J.; GÁllEGO, J. \&
PÓRTUS, M. 1999. Epidemiology of canine leishmaniosis in Catalonia (Spain). The example of the Priorat focus. Veterinary. Parasitology, 83: 87-97.

FLETCHER, K.C.; EUGSTER, A.K.; SCHMIDT, R.E. \& HUBBARD, G.B. 1979. Parvovirus infection in maned wolves. Journal of the American Veterinary Medical Association, 175: 897-900.

FUNK S.M.; FIORELLO C.V.; CLEAVELAND, S. \& GOMPPER, M.E. 2001. The role of disease in carnivore ecology and conservation. Pp. 443-466. In: J.L. Gittleman; S.M. Funk; R.K. Wayne \& D. Macdonald (eds). Carnivore Conservation. Cambridge University Press, Cambridge, UK. 675p.

GASCOYNE， S.C.; LAURENSON, M.K.; LELO, S. \& BORNER, M. 1993. Rabies in African wild dogs (Lycaon pictus) in the Serengeti region, Tanzania. Journal of Wildlife Diseases, 29: 396-402.

GILMOUR, J.S. \& MUNRO, R. 1991. Wildlife disease: management or masterly inactivity? Journal of Natural History, 25: 537-541.

GOMES-SOLECKI M.J.; WORMSER G.P.; PERSING D.H.; BERGER, B.W.; GLASS, J.D.; YANG, X.; DATTWYLER, R.J. 2001. A first-tier rapid assay for the serodiagnosis of Borrelia burgdorferi infection. Archives of Internal Medicine, 161: 20152020.

GOMES, A.A.B. 2004. Epidemiologia da raiva: caracterização de vírus isolados de animais domésticos e silvestres do semiárido paraibano da região de Patos, Nordeste do Brasil. Tese de Doutorado em Ciências. Faculdade de Medicina Veterinária e Zootecnia da Universidade de São Paulo, São Paulo, Brasil. 107p.

GORDON, J.C. \& ANGRICK, E.J. 1986. Canine parvovirus: Environmental effects on infectivity. American Journal of Veterinary Research, 47: 1464-1467.

GREENE, C.E. \& APPEL, M.J. 1998. Canine distemper. Pp. 9-22. In: C. E. Greene (ed.). Infectious diseases of the dog and cat. $2^{a}$ edição. W.B. Saunders, Philadelphia. 1424p.

GRENFELL, B.T. \& GULLAND, F.M.D. 1995. Introduction: Ecological Impact of parasitism on Wildlife Host Populations. Parasitology, 111: S3-S14.

GUERRA-NETO, G.; GIRIO, R.J.S.; ANDRADE, T.M.; KOPROSKI, L.P.; MORAES, W. \& SANTOS, L.C. 2004. Ocorrência de anticorpos contra Leptospira spp. em felídeos neotropicais pertencentes ao Criadouro de Animais Silvestres da 
Itaipu Binacional e ao Zoológico Municipal Bosque Guarani, Foz do Iguaçu, Estado do Paraná. ARS Veterinária, 20:75-80.

HARGIS, A.M. 1990. Sistema Tegumentar. Pp. 1-77. In: R.G. Thomson. Patologia Veterinária Especial. Editora Manole, São Paulo. 753p.

HAYDON, D.T.; CLEAVELAND, S.; TAYLOR, L.H. \& LAURENSON, M.K. 2002. Identifying reservoirs of infection: a conceptual and practical challenge. Emerging Infection Diseases, 8: $1468-1473$.

HELMBOLT, C.F. \& JUNGHERR, E.L. 1955. Distemper complex in wild carnivores simulating rabies. American Journal of Veterinary Research, 16: 463-469.

HERRERA, H.M.; ALESSI, A.C.; MARQUES, L.C.; SANTANA, A.E.; MENEZES, R.F.; MACHADO, R.Z. 2002. Experimental Trypanosoma evansi infection in South American coati (Nasua nasua): hematological, biochemical and histopathological changes. Acta Tropica, 81, 203- 210.

HERRERA, H.M.; AQUINO, L.P.; MENEZES, R.F.; MARQUES, L.C.; MORAES, M.A.; WERTHER, K. \& MACHADO, R.Z. 2001. Trypanosoma evansi experimental infection in the South American coati (Nasua nasua): clinical, parasitological and humoral immune response. Veterinary parasitology, 102: 209-16.

HOFMEYR, M.; BINGHAM, J.; LANE, E.P.; IDE, A. \& NEL, L. 2000. Rabies in African wild dogs (Lycaon pictus) in the Madikwe Game Reserve, South Africa. Veterinary Record, 146: 50-52.

HORSH, F. 1999. Leptospirose. Pp. 305-326. In: J. Beer (ed.). Doenças infecciosas em animais domésticos. Rocca, São Paulo. $398 \mathrm{p}$.

HYSLOP, N.S.G. 1955. Feline enteritis in the lynx, the cheetah and other wild felidae. British Veterinary Journal, 111: 373-377.

JANSSEN, D.L.; BARTZ, C.R.; BUSH, M.; MARCHWICKI, R.H.; GRATE, S.J. \& MONTALI, R.J. 1982. Parvovirus enteritis in vaccinated juvenile bush dogs. Journal of the American Veterinary Medical Association, 181: 1225-1227.

JORGE, R.S.P.; PEREIRA, M.S; MORATO R.G.; SCHEFFER K.C.; CARNIELI JR, P.; FERREIRA, F.; FURTADO, M.M.; KASHIVAKURA, C.K.; SILVEIRA, L.; JACOMO, A.T.A.; LIMA, E.S; PAULA, R.C. \& MAY-JUNIOR, J.A. no prelo. Detection of Rabies Virus Antibodies in Brazilian Free-Ranging Wild Carnivores. Jounal of Wildlife Diseases.
JOHNSON, M.R.; BOYD, D.K. \& PLETSCHER, D.H. 1994. Serologic investigations of canine parvovirus and caninedistemper in relation to wolf (Canis lupus) puppy mortalities. Journal of Wildlife Diseases, 30:270-273.

JORGE, R.S.P. 2008. Caracterização do estado sanitário dos carnívoros selvagens da RPPN SESC Pantanal e de animais domésticos da região. Tese de Doutorado. Programa de PósGraduação em Epidemiologia Experimental e Aplicada às Zoonoses da Faculdade de Medicina Veterinária e Zootecnia da Universidade de São Paulo, São Paulo, Brasil. 105p.

JORGE, R.S.P.; LIMA, E.S. \& LUCARTS, L.E.B. 2008. Sarna Sarcóptica ameaçando cachorros-vinagres (Speothos venaticus) de vida livre em Nova Xavantina - MT In: Anais do XXXIII Congresso Anual da Sociedade de Zoológicos do Brasil. Sorocaba, SP. (CD-ROM).

JORGE, R.S.P.; PEREIRA, M.S; MORATO R.G.; SCHEFFER K.C.; CARNIELI JR, P.; FERREIRA, F.; FURTADO, M.M.; KASHIVAKURA, C.K.; SILVEIRA, L.; JACOMO, A.T.A.; LIMA, E.S; PAULA, R.C. \& MAY-JUNIOR, J.A. No prelo. Detection of Rabies Virus Antibodies in Brazilian Free-Ranging Wild Carnivores. Jounal of Wildlife Diseases.

KAT, P.W.; ALEXANDER, K.A.; SMITH, J.S.; RICHRDSON, J.D. \& MUNSON, L. 1996. Rabies among African wild dogs (Lycaon pictus) in the Masai Mara, Kenya. Journal of Veterinary Diagnostic Investigation, 8: 420-426.

KOCK, R.; CHALMERS, W.S.K.; MWANZIA, J.; CHILLINGWORTH, C.; WAMBUA, J.; COLEMAN, P.G. \& BAXENDALE, W. 1998. Canine distemper antibodies in lions of the Masai Mara. Veterinary Record, 142: 662-665.

KRAKOWKA, S. \& KOESTNER, A. 1976. Age related susceptibility to canine distemper, virus infection in gnotobiotic dogs. Journal of Infectious Diseases, 134: 629-632.

LABRUNA, M.B.; JORGE, R.S.P.; SANA, D.A.; JACOMO, A.T.A.; KASHIVAKURA, C.K.; FURTADO, M.M.; FERRO, C.; PEREZ, S.A.; SILVEIRA, L.; SANTOS-JUNIOR, T.S.; MARQUES, S.R.; MORATO, R.G.; NAVA, A.; ADANIA, C.H.; TEIXEIRA, R.H.F.; GOMES, A.A.B.; CONFORTI, V.A.; AZEVEDO, F.C.C.; PRADA, C.S.; SILVA, J.C.R.; BATISTA, A.F.; MARVULO, M.F.V.; MORATO, R.L.G.; ALHO, C.J.R.; PINTER, A.; FERREIRA, P.M.; FERREIRA, F. \& BARROSBATTEST, D. M. 2005. Ticks (Acari:Ixodida) on Wild Carnivores in Brazil. Experimental and Applied Acaralogy, 36:149-163. 
LAINSON, R.; DYE, C.; SHAW, J.J.; MACDONALD, D.W.; COURTENAY, O.; SOUZA, A.A. \& SILVEIRA, F.T. 1990. Amazonian visceral leishmaniasis - distribution of the vector Lutzomyia longipalpis (Lutz \& neiva) in relation to the fox Cerdocyon thous (Linn.) and the efficiency of this reservoir host as source of infection. Memórias do Instituto Oswaldo Cruz, 85(1): 135-137.

LAURENSON, M.K.; MLENGEYA, T.; SHIFERAW, F.\& CLEAVELAND, S. 2005. Approaches to disease control in domestic canids for the conservation of endangered wild carnivores. Pp. 141-146. In: S.A. Osofsky; S. Cleaveland; W.B. Karesh; M.D. Kock; P.J. Nyhus; L. Starr \& A. Yang (eds.). Conservation and development interventions at the wildlife/ livestock interface: Implications for Wildlife, Livestock, and Human Health. IUCN Publications Sevices Unit, Gland, Switzerland and Cambridge, UK. 220p.

LAURENSON, K.; SHIFERAW, F. \& SILLERO-ZUBIRI, C. 1997. Disease, domestic dogs and the Ethiopian wolf: current situation. . Pp. 32-40. In: C.Sillero-Zubiri \& D.Macdonald (eds.).The ethiopian wolf. Status and conservation action plan. IUCN/SSC Canid Specialist Group, Gland, Switzerland. 123p.

LEIGHTON, F. \& KUIKEN, T. 2001. Leptospirosis. Pp.498-502. In: E.S. Williams \& I.K. Barker (eds). Infectious diseases of wild mammals. Iowa State University Press, Ames. 302p.

LEIGHTON, T.; FERGUSON, M.; GUNN, A.; HENDERSON, E. \& STENHOUSE, G. 1988. Canine distemper in sled dogs. Canadian Veterinary Journal, 29: 299.

LEVETT, P.N. 2001. Leptospirosis. Clinical Microbiology Reviews.14: 296-326.

LIMA, V.M.F.; FATTORI, K.R.; MICHELIN, A.F.; NOGUEIRA, F.S. \& SOUZA, L.O. 2009. Evidence of Leishmania spp. antibodies and DNA in bush Dogs (Speothos venaticus) in Brazil. Journal of Zoo and Wildlife Medicine, 40: 91-94.

LUPPI, M.M.; MALTA, M.C.; SILVA, T.M.; SILVA, F.L.; MOTTA, R.O.; MIRANDA, I.; ECCO, R. \& SANTOS, R.L. 2008. Visceral leishmaniasis in captive wild canids in Brazil. Veterinary Parasitology, 155:146-51.

MAIA, O.B. \& GOUVEIA, A.M.G. 2002. Birth and mortality of maned wolves Chrysocyon brachyurus (Illiger, 1811) in captivity. Brazilian Journal of Biology, 62: 25-32.

MANCIANTI, F.; MIGNONE, W. \& GALASTRI, F. 1994. Serologic survey for leishmaniasis in free-living red foxes (Vulpes vulpes) in Italy. Journal of Wildlife Diseases, 30: 454-456.
MANN, P.C.; BUSH, M.; APPEL, M.J.G.; BEEHLER, B.A.; MONTALI, R.J. 1980. Canine parvovirus infection in South American canids. Journal of the American Veterinary Medical Association, 177: 779-783.

MCCALLUM, H. \& DOBSON, A. 1995. Detecting disease and par- asite threats to endangered species and ecosystems. Trends in Ecology and Evolution, 10: 190-194.

MCCALlUM, H. \& DOBSON, A. 2002. Disease, habitat fragmentation and conservation. Proceedings of the Royal Society of London, 269: 2041-2049.

MECH, L.D. \& GOYAL, S.M. 1993. Canine parvovirus effect on wolf population change and pup survival. Journal Wildlife Diseases, 29: 330-333.

MEGID, J. 2007. Raiva. Pp. 785-798. In: Z.S. Cubas, J.C.R. Silva \& J.L. Catão-Dias (orgs.). Tratado de animais selvagens medicina veterinária. Editora Roca Ltda., São Paulo, SP. 1354p.

MITCHELL, M.A.; HUNGEFORD, L.L. \& NIXON, C. 1999. Serologic survey for selected infectious disease agents in raccoons from Illinois. Journal of Wildlife Diseases, 35: 347-355.

MOHEBALI, M.; HAJJARAN, H.; HAMZAVI, Y.; MOBEDI, I.; ARSHI, S.; ZAREI, Z.; AKHOUNDI, B.; NAEINI, K.M.; AVIZEH, R.\& FAKHAR, M. 2005. Epidemiological aspects of canine visceral leishmaniosis in the Islamic Republic of Iran. Veterinary Parasitology. 129: 243-251.

MORENO, J. \& ALVAR, J. 2002. Canine leishmaniasis: epidemiological risk and the experimental model. Trends in parasitology, 18: 399-404.

MÖRNER, T.; OBENDORF, D.L. \& ARTOIS, M. 2002. Surveillance and monitoring of wildlife diseases. Revue Scientifique et Technique de l'Office International des Epizooties, 21: 67-76.

MURRAY, D.L.; KAPKE, C.A.; EVERMAN, J.J. \& FULLER, T.K. 1999. Infectious disease and the conservation of free-ranging large carnivores. Animal Conservation, 2: 241-254.

NAVA, A.F.; CULLEN, L.JR.; SANA, D.A.; NARDI, M.S.; FILHO, J.D.; LIMA, T.F.; ABREU, K. C. \& FERREIRA, F. 2009. First evidence of canine distemper in Brazilian free-ranging felids. Ecohealth, 5: 513-518.

NIELSEN, J.N.; ARMSTRONG, C.H. \& NIELSEN, N.C. 1989. Relationship among selected Leptospira interrogans serogroups as determined by nucleic acid hybridization. Journal of Clinical Microbiology, 27: 2724-2729. 
OLIVEIRA, T.G. 1994. Neotropical Cats: Ecology and Conservation. EDUFMA, São Luís, MA. 220p.

PARRISH, C.R. \& CARMICHAEL, L.E. 1983. Antigenic structure and variation of canine parvovirus type-2, feline panleukopenia virus, and mink enteritis virus. Virology, 129: 401-414.

PARRISH, C.R. 1990. Emergence, natural history, and variation of canine, mink, and feline parvoviruses. Advances in Virus Research, 38: 403-450.

PATZ, J.A.; DASZAK, P; TABOR, G.M.; AGUIRRE, A.A.; PEARL, M.; EPSTEIN, J.; WOLFE, N.D.; KILPATRICK, A.M.; FOUFOPOULOS, J.; MOLYNEUX, D. \& BRADLEY, D.J. 2004. Unhealthy landscapes: policy recommendations on land use change and infectious disease emergence. Environmental Health Prespectives, 112: 1092-1098.

PATZ, J.A.; GRACZYK, T.K.; GELLER, N. \& VITTOR, A.Y. 2000: Effects of environmental change on emerging parasitic diseases. International Journal of Parasitology, 30: 1395-1405

PENCE, D.B. \& WINDBERG, L.A. 1994. Impact of a Sarcoptic Mange Epizootic on a Coyote Population. Journal of Wildlife Management, 58: 624-633.

POLLOCK, R.H.V. \& CARMICHAEL, L.E. 1990. Canine viral enteritis. Pp. 268-287. In: C.E. Greene (ed.). Infectious diseases of the dog and cat. W.B. Saunders, Philadelphia. 1424p.

PORTÚS, M.; GALLEGO, M.; RIERA, C.; AISA, M.J.; FISA, R. \& CASTILLEJO, S. 2002. Wild and domestic mammals in the life cycle of Leishmania infantum in southwest Europe. A literature review and studies performed in Catalonia (Spain). Revista Ibérica de Parasitologia, 62: 72-76.

POULIN, R. 1997. Species Richness of Parasite Assemblages: Evolution and Patterns. Annual Reviews Ecological Systems, 28 : 341-358.

RANDALL, D.A.; MARINO, J.; HAYDON, D.T.; SILLEROZBIRI, C.; KNOBEL, D.L., TALLENTS, L.A.,MACDONALD, D.W. \& LAURENSON, M.K. 2006. An integrated disease management strategy for the control of rabies in Ethiopian wolves. Biological Conservation, 131: 151-162.

RANDOLPH, S.E.; CHEMINI, C.; FURLANELLO, C.; GRNCHI, C.; HAILS, R.S.; HUDSON, P.J.; JONES, L.D.; MEDLEY, G.; NORMAN, R.A.; RIZZOLI, A.P.; SMITH G. \& WOOLHLOUSE, M.E.J. 2003. The Role of Pathogens in Biological Conservation. Pp. 139-150. In: P.J. Hudson, A.
Rizzoli, B.T. Grenfell, H. Heesherbeek \& A.P. Dobson. (eds.). The Ecology of Wildlife Diseases. Oxford University Press, Oxford, Great Britain. 218p.

ROBINSON, W.F.; WILCOX, G.E. \& FLOWER, R.L.P. 1980. Canine parvoviral disease: Experimental reproduction of the enteric form with a parvovirus isolated from a case of myocarditis. Veterinary Pathology, 17: 589-599.

ROELKE-PARKER, M.E.; MUNSON, L.; PACKER, C.; KOCK, R.; CLEAVELAND, S.; CARPENTER, M.; O'BRIEN, S.J.; POSPISCHIL, A.; HOFFMANN-LEHMANN, R.; LUTZ, H.; MWAMENGELE, G.L.M.; MGASA, M.N.; MACHANGE, G.A.; SUMMERS, B.A. \& APPEL M. J.G. 1996. A canine distemper virus epidemic in Serengeti lions (Panthera leo). Nature, 379: 441-445.

RÖKEN, B.O. 1993. Parasitic Diseases of Carnivores. Pp. 399-404. In: M. E. Fowler (ed.) Zoo \& Wild Animal Medicine: Current Therapy 3. W.B. Saunders Company, Philadelphia. 617p. ROTH, E.E. 1972. Leptospirosis. Pp. 356-368. In: J. W. Davis, L. H. Karstad \& D. O. Trainer (eds.). Enfermidades Infecciosas de los mamíferos Salvajes. Editora Acribia, Barcelona. 513p.

RUPPRECHT, C.E.; STÖRH, K. \& MEREDITH, C. 2001. Rabies. Pp. 3-36. In: E.S. Williams, I.K. Barker (eds). Infectious diseases of wild mammals. ( $3^{\text {a }}$ edição). Iowa State University Press, Ames. 302p.

SEMIÃO-SANTOS, S.J.; ABRANCHES, P.; SILVA-PEREIRA, M.C.D.; SANTOS-GOMES， G.M.; FERNANDES， J.P. \& VETTER, J.C.M. 1996. Reliability of serological methods for detection of Leishmaniasis in Portuguese domestic and wild reservoirs. Memórias do Instituto Oswaldo Cruz, 91: 747-750.

SENDA, M.; HIRAYAMA, N.; ITOH, O. \& YAMAMOTO, H. 1988. Canine parvovirus: Strain difference in haemagglutination activity and antigenicity. Journal of General Virology, 69: 349-354.

SILLERO-ZUBIRI, C.; MACDONALD, D.W. \& KING, A.A. 1996. Rabies and mortality in ethiopian wolves (Canis simensis). Journal of Wildlife Diseases, 32: 80-86.

SILVEIRA, F.T.; LAINSON, R., SHAW, J.J. \& POVOA, M.M. 1982. Leishmaniasis in Brazil: XVIII. Further evidence incriminating the fox Cerdocyon thous as a reservoir of Amazonian visceral leishmaniasis. Transactions of the Royal Society of Tropical Medicine and Hygiene, 76: 830-832.

SMITH, G.C. \& HARRIS, S. 1991. Rabies in urban foxes (Vulpes vulpes) in Britain: the use of a spatial stochastic 
simulation model to examine the pattern of spread and evaluate the efficacy of different control regimes. Philosophical Transactions of the Royal Society London, 334: 459-479.

SMITH, J.S. \& BAER, G.M. 1988. Epizootiology of rabies: the Americas. Pp. 365-380. In: J.B. Campbell \& K.M. Charlton (eds.). Rabies. Kluwer Academic Publishers, Boston. 431p.

SOBRINO, R.; FERROGLIO, E.; OLEAGA, A.; ROMANO, A.; MILLAN, J.; REVILLA, M.; ARNAL, M.C.; TRISCIUOGLIO A. \& GORTÁZAR, C. 2008. Characterization of widespread canine leishmaniasis among wild carnivores from Spain. Veterinary parasitology, 155: 198-203.

SOUZA JUNIOR, M.F.; LOBATO, Z.I.P. \& LOBATO, F.C.F. 2006. Presença de anticorpos da classe IgM de Leptospira interrogans em animais silvestres do Estado do Tocantins, Revista da Sociedade Brasileira de Medicina Tropical, 39: 292-294.

SOUZA, G.D.; SANTOS, E. \& ANDRADE FILHO, J.D. 2009. The first report of the main vector of visceral leishmaniasis in America, Lutzomyia longipalpis (Lutz \& Neiva) (Diptera: Psychodidae: Phlebotominae), in the state of Rio Grande do Sul, Brazil. Memórias do Instituto Oswaldo Cruz, 104: 1181-1182.

STEINEL, A.; PARRISH, C.R.; BLOOM, M.E.; TRUYEN, U. 2001. Parvovirus infections in wild carnivores. Journal of Wildlife Diseases, 37: 594-607.

STORTS, R.W. 1990. Sistema Nervoso Central. Pp. 579-643. In: R.G. Thomson (ed.). Patologia Veterinária Especial. Editora Manole Ltda., São Paulo, SP. 753p.

TABOR, G.M. 2002. Defining Conservation Medicine. Pp. 8-16. In: A.A. Aguirre, R.S. Ostfeld, G.M. Tabor, C. House \& M.C. Pearl (eds). Conservation medicine: ecological health in practice. Oxford University Press, New York. 432p.

TAYLOR, L.H.; LATHAM, S.M. \& WOOLHOUSE, M.E.J. 2001. Risk factors for human disease emergence. Philosophical Transactions of the Royal Society of London. Series B, Biological. Science, 356: 983-989.

THIERMANN, A.B. 1984. Leptospirosis: current developments and trends. Journal of the American Veterinary Medical Association, 184: 722-725.

THOMAS, N.J.; FOREYT, W.J.; EVERMANN, J.F.; WINDBERG, L.A. \& KNOWTON, F.F. 1984. Seroprevalence of canine parvovirus in wild coyotes from Texas, Utah, and Idaho (1972 to 1983). Journal of the American Veterinary Medical Association, 185: 1283-1287.
THORNE, E.T \& WILLIAMS, E.S. 1988. Disease and endangered species: the black-footed ferret as a recent example. Conservation biology, 2: 66-74.

TISCHENDORF, L.; THULKE, H.H.; STAUBACH, C.; MULLER, M.S.; JELTSCH, F. ; GORETZKI, J.; SELHORST, T.; MULLER, T.; SCHLÜTER, H. \& WISSEL, C. 1998. Chance and risk of controlling rabies in large-scale and long-term immunized fox populations. Proceedings of the Royal Society London Series B-Biological Sciences, 265: 839-846.

TOMA, B. \& ANDRAL, L. 1977. Epidemiology of fox rabies. Advanced Virus Research, 21: 1-36.

TRAVIS, D.A.; HUNGERFORD, L.; ENGEL, G.A.M \& JONESENGEL, L. 2006. Disease risk analysis: a tool for primate conservation planning and decision making. American Journal of Primatology, 68: 855-867.

TRUYEN, U.; EVERMANN, J.F.; VIELER, E. \& PARRISH, C.R. 1996. Evolution of canine parvovirus involved loss and gain of feline host range. Virology, 215: 186-189.

TRUYEN, U.; MULLER T.; HEIDRICH, R.; TACKMANN, K. \& CARMICHAEL, L.E. 1998. Survey on viral pathogens in wild red foxes (Vulpes vulpes) in Germany with emphasis on parvoviruses and analysis of a DNA sequence from a red fox parvovirus. Epidemiology and Infection, 121: 433-440.

VALENZUElA, D.; CEBALlOS, G. \& GARCIA, A. 2000. Mange Epizootic in White-nosed coatis in Western Mexico. Journal of Wildlife Diseases, 36: 56-83.

VAN DE BILDT, M.W.G.; KUIKEN, T.; VISEE, A.M.; LEMA, S.; FITZJOHN, T.R. \& OSTERHAUS, A.D.M.E. 2002. Distemper outbreak and its effect on African wild dog conservation. Emerging Infectious Diseases, 8: 211-213.

VASCONCELLOS, S. A. 1987. O papel dos reservatórios na manutenção da leptospirose na natureza. Comunicações Cientificas da Faculdade de Medicina Veterinária e Zootecnia da Universidade de São Paulo, 11: 17-24.

VOLTARELLI, E.M.; ARRAES, S.M.A.A.; PERLES, T.F.; LONARDONI, M.V.C.; TEODORO, U. \& SILVEIRA, T.G.V. 2009. Serological survey for Leishmania $s p$. infection in wild animals from the municipallity of Maringá, Paraná state, brazil. The Journal of Venomous Animals and Toxins including Tropical Diseases, 15: 732-744.

WANDELER, A.I. 1993. Wildlife rabies in perspective. Onderstepoort Journal of Veterinary Research, 60: 347-350. 
WANDELER, A.I., CAPT, S., GERBER, H., KAPPELER, A. \&

KIPFER, R. 1988. Rabies epidemiology, natural barriers and fox vaccination. Parasitologia, 30: 53-57.

WEBSTER, J.P.; ELLIS, W.A. \& MACDONALD, D.W. 1995. Prevalence of Leptospira spp. in wild brown rats (Rattus norvegicus) on UK farms. Epidemiology and Infection, 114: 195-201.

WEILER, G.J.; GARNER, G.W. \& RITTER, D.G. 1995. Occurrence of rabies in a wolf population in northeastern Alaska. Journal of Wildlife Diseases, 31: 79-82.

WHELAN, S.P.J. 2009. Rhabdoviruses. Pp. 145-162. In: C. Cameron, M. Gotte, K.D. Raney (eds). Viral Genome Replication. Springer, New York. 622p.

WILliAMS, E.S. 2001. Canine distemper. Pp. 50-59. In: E.S. Williams \& I.K. Barker (eds). Infectious diseases of wild mammals. $3^{a}$ edição. Iowa State University Press, Ames. 302p.

WILLIAMS, E.S.; THORNE, E.T.; APPEL M.J.G. \& BRLITSKY D.W. 1988. Canine distemper in black-footed ferrets (Mustela nigripes) from Wyoming. Journal of Wildlife Diseases, 24: 385398.

WOODROFFE, R. 1999. Managing disease threats to wild mammals. Animal Conservation, 2: 185-193.

WOODROFFE, R.; CLEAVELAND, S.; COURTENAY, O.; LAURENSON, M.K. \& ARTOIS, A. 2004. Infectious diseases. Pp. 123-142. In: D. W. Macdonald \& C. Sillero-Zubiri (eds.). The biology and conservation of wild canids. Oxford University Press, London. 468p.

Submetido em 25/03/2010 Aceito em 18/06/2010 